\title{
Theoretical and Experimental Parameters of the Structure and Crystallization Kinetics of Melt- Quenched As30Te64Ga6 Glassy Alloy
}

\author{
Abdelazim M. Mebed \\ Jouf University \\ Meshal Alzaid \\ Jouf University \\ R.M. Hassan \\ Abyan University \\ Alaa Abd-Elnaiem ( $\nabla$ abd-elnaiem@aun.edu.eg ) \\ Assuit University https://orcid.org/0000-0002-0882-5539
}

Original Research Full Papers

Keywords: As-Te-Ga glass, Thermal stability, Glass-forming ability, Isothermal parameters, Structure parameters

Posted Date: February 11th, 2021

DOl: https://doi.org/10.21203/rs.3.rs-205540/v1

License: (9) This work is licensed under a Creative Commons Attribution 4.0 International License. Read Full License

Version of Record: A version of this preprint was published at Journal of Inorganic and Organometallic Polymers and Materials on February 26th, 2021. See the published version at https://doi.org/10.1007/s10904-021-01938-x. 


\title{
Theoretical and Experimental Parameters of the Structure and Crystallization Kinetics of Melt-Quenched $\mathrm{As}_{30} \mathrm{Te}_{64} \mathrm{Ga}_{6}$ Glassy Alloy
}

\author{
Abdelazim M. Mebed ${ }^{1 *}$. Meshal Alzaid ${ }^{1}$. R.M. Hassan² . Alaa M. Abd-Elnaiem ${ }^{3 *}$ \\ ${ }^{1}$ Department of Physics, College of Science, Jouf University, Al-Jouf, Sakaka P.O. Box 2014, \\ Saudi Arabia \\ ${ }^{2}$ Physics Department, Faculty of Education-Zingiber, Abyan University, Yemen \\ ${ }^{3}$ Physics Department, Faculty of Science, Assuit University, Assiut 71516, Egypt \\ *Corresponding author \\ e-mail: abd-elnaiem@aun.edu.eg; ORCID: https://orcid.org/0000-0002-0882-5539
}

\begin{abstract}
The present framework reports the structural, fundamental parameters, and crystallization kinetics of the melt-quenched $\mathrm{As}_{30} \mathrm{Te}_{64} \mathrm{Ga}_{6}$ chalcogenide glass. The energy dispersive $\mathrm{X}$ ray analysis of the $\mathrm{As}_{30} \mathrm{Te}_{64} \mathrm{Ga}_{6}$ glassy system reveals that the constituent element ratio of the investigated bulk sample agrees with the nominal composition. Also, X-ray diffraction (XRD) and Differential Scanning Calorimetry (DSC) were used to characterize crystallization kinetics, and structural properties; respectively. Four characteristic temperatures related to various phenomena are observed in the investigated DSC traces. The first one is $T_{g}$ that corresponds to the glass transition temperature. The second one is $\left(T_{c 1}\right.$, and $\left.T_{c 2}\right)$ that corresponds to the onset of the double crystallization temperatures. The third one $\left(T_{P 1}\right.$, and $\left.T_{P 2}\right)$ identifies the double peak crystallization temperatures. The last characteristic temperature $\left(T_{m}\right)$ is the melting point. The XRD analysis indicates the amorphous structure of the as-prepared glassy alloy, while the annealed samples are polycrystalline. The crystallization kinetics of the As30 $\mathrm{Te}_{64} \mathrm{Ga}$ bulk are studied under non-isothermal conditions. In addition, the values of various kinetic parameters such as the glass transition activation energy, weight stability standard, and Avrami support were determined. The activation energy of the crystallization process for As30Te64Ga6 glass alloy was calculated using classical methods. The results indicated that the rate of crystallization is related to thermal stability and the ability to form glass. Kinetic parameters have been estimated with some conventional methods and found to be dependent on heating rates $(\beta)$.
\end{abstract}

Keywords As-Te-Ga glass. Thermal stability . Glass-forming ability . Isothermal parameters . Structure parameters 


\section{Introduction}

Chalcogenide-based materials are the subject of intensive studies because of their utilizing in potential technological applications specially in enhancing energy storage and solar cell [1-3], and optoelectronics Electrical switching [4]. Chalcogenide glasses are usually synthesized via mixing chalcogen elements in group VI (such as $\mathrm{S}$, Se, and $\mathrm{Te}$ ) with other elements. Chalcogenide materials are utilized for many electronic applications such as IR optical elements, switching devices, reversible phase change, optical fibers, transmission media, and records $[5,6]$. One of these materials, As-Te alloy that characterized by a high crystallization ability as well as a high glass-forming ability. Therefore, the formation of the As-Te alloys should be performed at relatively low temperatures [7]. The As-Te glassy alloys are commonly synthesized by the melt quenching technique even the concentration of As is constantly increased at the expense of the Te ratio [8].

In order to improve the physical properties of the binary As-Te system, doping with other elements or/and heating treatment are required. For example, the electrical response of the AsTe glassy system reinforces by doping $\mathrm{Cu}, \mathrm{Ge}, \mathrm{Si}$, or $\mathrm{Ga}$ elements, for this reason, the ternary alloys are beneficial in the electrical field not to mention the great benefit of these alloys, whether in the optical or thermal field [9-11]. The addition of such elements for forming ternary alloys leads to a change in the characteristic's temperatures such as $T_{g}$ [12]. Furthermore, the transformation from semiconductor to metal trend in the ternary glassy system As-Te-Al encourages after addition of the Al element to the As-Te system [13]. Studies of the physical properties, including the optical, electrical, and structural properties of the As-Te-Ga system is limited [11, 14-17]. For example, some efforts have been done to study the effect of heat treatment (e.g. annealing) on the optical properties for few compositions of As-Te-Ga thin films $[11,16,18]$. To the best of our knowledge, the thermal analysis and crystallization kinetics of the As-Te-Ga system has not been extensively investigated [19]. Thus, thermal kinetics and analysis is an important tool that helps for predicting the structure of the bulk alloys and hence modifying the performance of the material under investigation. Accordingly, the study of thermal analysis and crystallization kinetics of As-Te-Ga is very important because it could help in further progress in the development of many physical properties and technological applications based on the As-Te-Ga system.

Moreover, after listing the physical properties and mentioned scientifically interesting contours of the studied glass system, it is worth noting here for several thermal parameters and the main concepts for glass transformation and crystallization process, i.e. thermal stability of 
chalcogenide glassy alloys. Thermal stability has a magnificent benefit in several technological applications. This is due to determine the useful ranging of working temperatures via the structure changes and thus definitive crystallization for the operating temperatures. Consequently, amorphous materials seek to complete the transformation to the crystalline state in order to stabilize. In all the solid-state systems, thermally activated transformations can be studied via isothermal and non-isothermal examinations [20-22]. In the isothermal methods, the investigated glassy alloys are brought quickly to a temperature above the temperature of the glass transition, and then the resulted heat as a function of time is recorded to observe the crystallization processes. The isothermal techniques have a clear disadvantage presentation in the impossibility of reaching an exam temperature immediately and during the periods in which the glassy system needs to stabilize. In contrast, the constant heating rate experiments do not have the mentioned drawback [23]. Generally, the differential thermal analysis (DTA) and DSC are the common techniques used for investigating the phase transitions and the crystallization kinetics of the chalcogenide glasses and polymers among other techniques [22, 24-27].

The main aims of the present work: (1) investigate the theoretical and physical aspects of the structure of the $\mathrm{As}_{30} \mathrm{Te}_{64} \mathrm{Ga}_{6}$ system, (2) study the crystallization kinetics, and thus evaluate the crystallization parameters of $\mathrm{As}_{30} \mathrm{Te}_{64} \mathrm{Ga}_{6}$ glassy alloy via DSC under a nonisothermal method, (3) determine the crystal structure for the as-prepared and annealed bulk samples in terms of the XRD measurements via $\mathrm{Cu}-\mathrm{K}_{\alpha}$ radiation, and (4) evaluate the thermal stability, glass-forming ability, and other thermal criteria for the $\mathrm{As}_{30} \mathrm{Te}_{64} \mathrm{Ga}_{6}$ system.

\section{Experimental details}

\subsection{Samples preparations}

The bulk of the $\mathrm{As}_{30} \mathrm{Te}_{64} \mathrm{Ga}_{6}$ glassy alloy is formed by the conventional melt quenching method from a high-purity ( $99.999 \%)$ of As, Te, and Ga (purchased from Sigma-Aldrich Company). The powders of As, Te, and $\mathrm{Ga}$ are weighted accordingly to their atomic concentrations (at.\%) and then put into a clean silica-glass ampoule. After that, the ampoule is closed when the inside vacuum reached $10^{-5}$ Torr. Then the mixture is melted by introducing into a controlled furnace at $1100 \mathrm{~K}$ for $24 \mathrm{~h}$. Through the melting process, the ampoule is frequently shaken to intermix the constituents and to increase the homogenization of the As30Te ${ }_{64} \mathrm{Ga}_{6}$ alloy. Finally, after this treatment, the melt is followed by quick quenching in an ice-water mixture to avoid the crystallization process through the melt solidification. The 
thermal annealing of the bulk samples of $\mathrm{As}_{30} \mathrm{Te}_{64} \mathrm{Ga}_{6}$ glass is carried out at selected annealing temperatures of 450,475 , and $575 \mathrm{~K}$ for $1 \mathrm{~h}$ under a vacuum of $10^{-5}$ Torr.

\subsection{Samples characterizations}

The concentration of elements in the as-prepared bulk sample is examined by the energy dispersive X-ray (EDX) spectroscopy. Whereas, the crystal structures of the as-prepared, as well as the annealed $\mathrm{As}_{30} \mathrm{Te}_{64} \mathrm{Ga}$ 6 samples, are identified using a Phillips X-ray diffractometer. The X-ray diffractometer is composed of a $\mathrm{Cu}-\mathrm{K}_{\alpha}$ radiation source with a graphite monochromator and the radiation wavelength $(\lambda)$ equals $1.54178 \AA$. The XRD measurements are performed within the range of $2 \theta=10-70^{\circ}$ with a scanning step and speed of $0.02^{\circ}$, and $0.06^{\circ} \mathrm{s}^{-1}$, respectively.

The characteristic temperatures, phase change, and crystallization kinetics are investigated based on the monitored DSC (Model: TA - Q20). For this objective, around $10 \mathrm{mg}$ of the $\mathrm{As}_{30} \mathrm{Te}_{64} \mathrm{Ga}_{6}$ glass sample is used for each $\beta$ (ranging from 5 to $25 \mathrm{~K} \mathrm{~min}^{-1}$ ), and the heat scanning was recorded from 310 to $675 \mathrm{~K}$. The value of $T_{g}$, crystallization onset temperatures $\left(T_{c 1}\right.$, and $\left.T_{c 2}\right)$, the crystallization peak temperatures $\left(T_{P 1}\right.$, and $\left.T_{P 2}\right)$ for the first and second crystallization peaks, respectively, and the melting temperature $\left(T_{m}\right)$ are deduced with an accuracy of $\pm 1 \mathrm{~K}$ by the microprocessor of the thermal analyzer.

\section{Results and discussion}

\subsection{Theoretical aspects of the structure of the $\mathrm{As}_{30} \mathrm{Te}_{64} \mathrm{Ga}_{6}$}

\subsubsection{The coordination number and the number of constraints}

The coordination number $\langle\mathrm{r}>$ is defined as the average distance between the adjacent atoms of the components of a substance and describes the properties of the covalent chains that make up the glass [28]. Accordingly, the value of $\langle r\rangle$ for the As30Te64 ${ }_{4} \mathrm{Ga}_{6}$ alloy have been computed using the subsequence equation [29]:

$<r>=\frac{\alpha N_{A s}+\beta N_{T e}+\gamma N_{G a}}{\alpha+\beta+\gamma}$

Here $\alpha, \beta$ and $\gamma$ are the atomic ratios of $\mathrm{As}, \mathrm{Te}$, and $\mathrm{Ga}$, and in the present study are proposed to be 30,64 , and 6 at. $\%$, while $N_{A s}, N_{T e}$, and $N_{G a}$ denote their coordination number and equal to 3,2, and 5, respectively. The deduced value of $\langle r\rangle$ for the studied system is 2.48 and this is greater than the critical value (2.4), which is known as the rigidity percolation threshold (RPT). Based on the $\langle r\rangle$ value, the atoms in the proposed $\mathrm{As}_{30} \mathrm{Te}_{64} \mathrm{Ga}$ g glass overconstrained or rigidly connected. In an optimal glass configuration, the mechanical constraints, i.e., the bond expansion constraints $\left(\mathrm{N}_{\alpha}\right)$ and the bond flexion constraints $\left(\mathrm{N}_{\beta}\right)$ of each atom are 
enumerated by $N_{\alpha}=\left\langle r>/ 2\right.$ and $N_{\beta}=[2<r>-3$ ] [30], and equals to 1.24 and 1.96 for the As30 $\mathrm{Te}_{64} \mathrm{Ga}$ g glass, respectively. The average number of constraints is $N_{c o n}=N_{\alpha}+N_{\beta}$, and also can be expressed by the following equation [31]:

$N_{\text {con }}=\frac{5}{2}<r>-3$

Both the two equations give the same value (3.2) of $N_{\text {con }}$ for the studied As30Te ${ }_{64} \mathrm{Ga}_{6}$ system.

\subsubsection{Lone pair electrons}

In chalcogenide material, the lone pair electrons $\left(L_{P}\right)$ are responsible for the glass formation. It was proposed [29], that the $L_{P}$ is a number must be $>1$ for the ternary system. The value of $L_{P}$ in the present work is computed by the subsequence equation [32]:

$L_{P}=V-<r>$

where $V$ is the valence electrons and given from [32]:

$V=\frac{\alpha[V]_{A S}+\beta[V]_{T e}+\gamma[V]_{G a}}{\alpha+\beta+\gamma}$

Here $[V]_{A s},[V]_{T e}$, and $[V]_{G a}$ are the valence of As, Te, and Ga and equals 5, 6, and 3, respectively, while $\alpha, \beta$, and $\gamma$ are their atomic concentrations. Accordingly, the values of $V$ and $L_{P}$ for the studied glass are equal to 5.52 and 3.04, respectively. It is observed that the computed value of $L_{P}$ for $\mathrm{As}_{30} \mathrm{Te}_{64} \mathrm{Ga}$ alloy is much greater than 1 (value of $L_{P}$ for ideal glass in the ternary system), this emphasizes that the proposed $\mathrm{As}_{30} \mathrm{Te}_{64} \mathrm{Ga} 6$ composition strongly tends to be formed in the amorphous nature.

\subsubsection{The deviation of stoichiometry}

The deviation of stoichiometry $(S)$ is given by the ratio of covalent bonding possibilities of chalcogen atom, such as $T e$ in the present system, to that of a non-chalcogen atom, such as As and Ga. The value of $S$ is computed using the subsequence equation [33]:

$S=\frac{\alpha N_{T e}}{\beta N_{A S}+\gamma N_{G a}}$

For $S>1$, the system is considered as chalcogen-rich and for $S<1$, the system is considered chalcogen-poor, while at $S=1$, the system is stoichiometry. The obtained value of $S$ equals 1.07 and hence the $\mathrm{As}_{30} \mathrm{Te}_{64} \mathrm{Ga}_{6}$ glass belongs to the chalcogen-rich type.

\subsubsection{The average heat of atomization}

The average heat of atomization $\left(\bar{H}_{S}\right)$ for the $\mathrm{As}_{30} \mathrm{Te}_{64} \mathrm{Ga}_{6}$ glassy system can be evaluated from Eq. (6) [34]:

$\bar{H}_{S}=\frac{\alpha\left[H_{S}\right]_{A S}+\beta\left[H_{S}\right]_{T e}+\gamma\left[H_{S}\right]_{G a}}{\alpha+\beta+\gamma}$ 
The values of heat of atomization of individual elements As, Te, and Ga equal to 72.37, 47.03, and $65.06 \mathrm{kcal} \mathrm{mol}^{-1}$, respectively [34]. The estimated values of $\bar{H}_{S}$, and the average single heat of atomization $\left(\frac{\bar{H}_{S}}{\langle r\rangle}\right)$ equal to 55.71 and $22.47 \mathrm{kcal} \mathrm{mol}^{-1}$, respectively.

\subsubsection{The bond energy}

The bond energies for heteronuclear bonds $\left(D_{(A-B)}\right)$ have been determined using Pauling's relation [35]:

$D_{(A-B)}=\sqrt{D_{(A-A)} \times D_{(B-B)}}+30\left(\chi_{A}-\chi_{B}\right)^{2}$

where $D_{(A-A)}$ and $D_{(B-B)}$ are the bond energies of the homonuclear bonds, while $\chi_{A}$ and $\chi_{B}$ are the values of electronegativities of $A$ and $B$ elements, respectively. The heteronuclear bonds in $\mathrm{As}_{30} \mathrm{Te}_{64} \mathrm{Ga}_{6}$ are 90, 30, and 4 bonds for $(A s-T e),(T e-G a)$, and (Te-Te), respectively. In another hand, the bond energies for heteronuclear bonds are $D_{(A s-T e)}$ and $D_{(T e-G a)}$ and equal to 75.61 and $42.13 \mathrm{kcal} \mathrm{mol}^{-1}$, respectively, while $D_{(A s-A s)}, D_{(T e-T e)}$ and $D_{(G a-G a)}$ equal to 92.30, 61.62, and $25.46 \mathrm{kcal} \mathrm{mol}^{-1}$ and $\chi_{A s}, \chi_{T e}$ and $\chi_{G a}$ equal to 2.18, 2.10, and 1.81, respectively.

\subsubsection{The cohesive energy}

The cohesive energy $(C E)$ is referring to the energy needed to separate constituent atoms away from each other and to bring them to an assembly of neutral free atoms. The value of $C E$ gives information about the chemical stability of the material which is deduced by summing the bond energies of all the bonds expected in the material under consideration as shown in Eq. (8) [36]:

$C E=\frac{\sum\left(C_{i} D_{i}\right)}{100}$

Here $C_{i}$ is the number of expected chemicals and bonds mentioned above in section 3.1.5. In As $30 \mathrm{Te}_{64} \mathrm{Ga}_{6}, D_{i}$ is the energy of each bond and equal to $75.61,42.13$, and $61.62 \mathrm{kcal} \mathrm{mol}^{-1}$ for (As-Te), (Te-Ga), and (Te-Te) bonds, respectively. The estimated value of $C E$ for $\mathrm{As}_{30} \mathrm{Te}_{64} \mathrm{Ga} 6$ glassy equals $83.15 \mathrm{kcal} \mathrm{mol}^{-1}$.

\subsubsection{The fraction of floppy modes and cross-linking density}

Thorpe [37] suggested that there is a finite fraction of the modes of normal zerofrequency vibration called floppy modes $(f)$. These floppy modes are found in the absence of weaker long-range forces and the $f$ fractions are given by:

$f=\frac{12-5<r>}{6}$ 
Using $\langle r\rangle=2.48$ for the $\mathrm{As}_{30} \mathrm{Te}_{64} \mathrm{Ga}_{6}$ glassy, hence the value of the fraction of floppy modes equals -0.07 . This means that the system has high rigidity. Moreover, the cross-linking density $(X)$ can be obtained from the following expression:

$X=<r>-2$

The deduced value of $X$ for the $\mathrm{As}_{30} \mathrm{Te}_{64} \mathrm{Ga}_{6}$ system is 0.48 .

\subsubsection{The electronegativity}

According to principle Sanderson [38], the electronegativity $\left(\chi_{C M}\right)$ of the studied glassy system has been obtained from the following relation:

$\chi_{C M} \approx\left(\prod_{k=1}^{P} \chi_{k}\right)^{\frac{1}{P}}$

If the molecule contains $P$ atoms (same and/or different), the value of $k$ will equal $1,2, \ldots, P$,

while $\chi_{k}$ denote their isolated atom electronegativities. The obtained $\chi_{C M}$ for $\mathrm{As}_{30} \mathrm{Te}_{64} \mathrm{Ga}_{6}$ equals 2.04 where $\chi_{A s}, \chi_{T e}$ and $\chi_{G a}$ equal to $2.18,2.10$, and 1.81 , respectively.

\subsection{Elemental analysis}

The EDX analysis is used for the quantitative elemental composition of the as-prepared As30Te ${ }_{64} \mathrm{Ga} 6$ alloy as shown in Fig. 1. The EDX chart reveals the spectral distribution of the constituent element and the atomic percentage ratio for As, Te, and Ga found to equals 30.13, 63.93, and 5.94 at.\%, respectively. The percentage errors of the proposed concentrations are $0.43,0.11$, and $1 \%$ for As, Te, and Ga, respectively.

\subsection{The crystal structure of the $\mathrm{As}_{30} \mathrm{Te}_{64} \mathrm{Ga}_{6}$ bulk alloy}

The crystal structure (either amorphous or crystalline) of the as-prepared and annealed $\mathrm{As}_{30} \mathrm{Te}_{64} \mathrm{Ga}_{6}$ bulk system is confirmed by the XRD measurements as shown in Fig. 2. The absence of any sharp peak in the XRD plot of the as-prepared sample confirms the noncrystalline structure (amorphous) of the as-prepared melt-quenched As30Te64Ga6 alloy. Whereas, the XRD charts of annealed samples at 450, 475, and $575 \mathrm{~K}$ reveal few sharp as well as small peaks as shown in Fig. 2. The annealing temperatures were selected to cover both the two crystallization peaks according to the DSC traces (see Fig. 3). The presence of these diffraction peaks attributed to the partial transition from amorphous to the polycrystalline state during the annealing process of the $\mathrm{As}_{30} \mathrm{Te}_{64} \mathrm{Ga}_{6}$ bulk sample. The diffraction of dominant 
peaks for an annealed sample at $450 \mathrm{~K}$ was indexed with the monoclinic $\mathrm{As}_{2} \mathrm{Te}_{3}$ phase associated with the diffraction plane (112) [No. card: 87-0374] and hexagonal Ga7Te 10 phase associated with diffraction plane (205) [No. card: 85-0007]. Whereas an annealed As $30 \mathrm{Te}_{64} \mathrm{Ga} 6$ glass at $475 \mathrm{~K}$ reveals the formation of the As2 $\mathrm{Te}_{3}$ phase with hexagonal (110) and monoclinic (513) crystal structures [No. card: 87-0374] together with the hexagonal Ga2Te5 phase associated with miller indices of (101), and (102) [No. card: 45-0954], and hexagonal Ga7Te 10 phase with miller indices of (102) [No. card: 85-0007]. Besides, there is a peak observed for the monoclinic GaTe phase with miller indices (102) [No. card: 44-1127]. The annealing of the $\mathrm{As}_{30} \mathrm{Te}_{64} \mathrm{Ga}_{6}$ sample at $575 \mathrm{~K}$ leads to the formation of monoclinic $\mathrm{As}_{2} \mathrm{Te}_{3}$ phases corresponding to miller indices of (110) with card [No. card: 87-0374], and (513) with card [No. card: 72-1685], hexagonal Ga2Te5 phase observed at (102) with card [No: 45-0954], and (101) with card [No: 45-0954], monoclinic GaTe phase observed at (620) with card [No. card: 71-0626] and (250) with card [No. card: 75-2220] along with their respective $2 \theta$ value (JCPDS database, 1998) as shown in Fig. 2. The observed phases are denoted by popular symbols in the XRD charts in Fig. 2, while the crystal structure parameters such as the average crystallite size, interplanar distance, strain, dislocation density, etc., were determined in our previous work [18].

\subsection{The thermal analysis of $\mathrm{As}_{30} \mathrm{Te}_{64} \mathrm{Ga}_{6}$ bulk alloy \\ 3.4.1 DSC experiments data}

To study the crystallization kinetics of melt-quenched As30Te ${ }_{4} \mathrm{Ga}_{6}$ chalcogenide glassy and confirming its glassy nature, DSC of $\mathrm{Ass}_{30} \mathrm{Te}_{64} \mathrm{Ga}_{6}$ at $\beta$ started from 5 to $25 \mathrm{~K} \mathrm{~min}^{-1}$ and in the temperature range, $310-670 \mathrm{~K}$ is carried out as presented in Fig. 3. It is observed for all values of $\beta$, four characteristic phenomena are detected in the investigated temperature range for the $\mathrm{As}_{30} \mathrm{Te}_{64} \mathrm{Ga}$ system. The first one $\left(T_{g}\right)$ corresponds to the glass transition which is associated with absorbing energy to overcome the rigidity of the lattice. The second one $\left(T_{c 1}\right.$ and $T_{c 2}$ ) corresponds to the onset of the crystallization temperatures for the first and second crystallization peaks, respectively. The third characteristic temperature $\left(T_{P 1}\right.$ and $\left.T_{P 2}\right)$ identifies the peak crystallization temperatures for the two observed crystallization stages. The last characteristic temperature $\left(T_{m}\right)$ is the melting point. As mentioned, the DSC thermo-grams reveal a single glass transition, while two exothermic crystallization peaks. The values of the characteristic temperatures $\left(T_{g}, T_{c 1}, T_{c 2}, T_{P 1}, T_{P 2}\right.$ and $\left.T_{m}\right)$ of the studied glassy system at different $\beta$, are estimated from the DSC traces and listed in Table 1. From Table 1, it is observed those values are shifted to a higher temperature with the increase of $\beta$. This 
observation confirmed that all these transitions and transformations are thermally activated. The observation of two endothermic peaks for the melting phenomena could be attributed to the formation of more than one phase through the heating which is confirmed by the XRD analysis. The existence of a single $T_{g}$ reveals that the formed $\mathrm{As}_{30} \mathrm{Te}_{64} \mathrm{Ga} 6$ glass is more stable than those glasses revealing multi- $T_{g}$. The concentration of $\mathrm{Ga}$ in the As-Te-Ga alloys affect the number of crystallization peaks, as there is one, or two crystallization peaks observed for the $\mathrm{As}_{30} \mathrm{Te}_{70}, \mathrm{As}_{30} \mathrm{Te}_{67} \mathrm{Ga}_{3}$, and $\mathrm{As}_{30} \mathrm{Te}_{60} \mathrm{Ga}_{10}$ glasses at different $\beta$ [16, 39-41]. It was observed the value of characteristics temperatures are shifted to higher values as the Ga concentration increase or Te decrease at the same $\beta$.

\subsubsection{Thermal stability parameters}

The common criterion employed to obtain the glass thermal stability against crystallization is Deiztal's criterion, which is defined by the subsequent equation [42]:

$\Delta T=T_{c}-T_{g}$

The glassy becomes more stable as $\Delta T$ increases. The obtained values of the thermal stability $\Delta T\left(\Delta T_{1}\right.$, and $\left.\Delta T_{2}\right)$ based on both crystallization peaks for the studied system are computed and summarized in Table 2 . The values of $\Delta T_{1}$, and $\Delta T_{2}$ increase as presented in Table 2 with the increase in $\beta$. In other words, the glass thermal stability against crystallization is improved with increasing $\beta$. The investigated glassy alloy is more stable whenever the $\beta$ increase but the tendency for stability is more for the difference $\Delta T_{2}$ compared to the difference $\Delta T_{1}$.

There are two other criteria that give information about thermal stability, which was obtained by Saad and Poulain [43]. The first one is called the S-parameter $\left(S_{P}\right)$ while the second is called the weighted thermal stability criterion $\left(H^{\prime}\right)$, and they are expressed by:

$S_{P}=\left(T_{p}-T_{c}\right) \cdot \frac{\Delta T}{T_{g}}=\frac{\left(T_{p}-T_{c}\right)\left(T_{c}-T_{g}\right)}{T_{g}} ; H^{\prime}=\frac{\Delta T}{T_{g}}$

The thermal stability $S_{P}$ reveals the resistance to devitrification after the formation of the glass. The difference between $T_{p}$, and $T_{c}$ in Eq. (13), is related to the rate of devitrification transformation of the glassy phases. The values of $S_{P}\left(S_{P 1}\right.$, and $\left.S_{P 2}\right)$ and $H^{\prime}\left(H_{1}^{\prime}\right.$, and $\left.H_{2}^{\prime}\right)$ for the As30Te ${ }_{64} \mathrm{Ga}_{6}$ glassy system at different $\beta$ are computed for both crystallization stages and presented in Table 2. It has been observed that the values of $S_{P 1}, S_{P 2}, H_{1}^{\prime}$, and $H_{2}^{\prime}$ are increased with the increase in $\beta$. These combined reasons and all these criteria in both crystallization stages are utilized to determine the stability in terms of the $\beta$ in the studied glassy alloy. In the sense that the studied system has two stages of stability but the first stability does not last long and the studied system is more stable at the second crystallization stage. Compared to other 
studied compositions of As-Te-Ga glasses, the increase of Ga or decrease in Te enhances the thermal stability of the formed glass [16, 39-41].

\subsubsection{Hrubý criterion and the glass-formation factor}

Hrubý's criterion $\left(H_{r}\right)$ which utilized to determine the thermal stability of the glass via the characteristic temperatures according to the following relation [44]:

$H_{r}=\frac{\Delta T}{T_{m}-T_{p}}=\frac{T_{c}-T_{g}}{T_{m}-T_{p}}$

On the other side, the glass-formation factor or ability parameter $\left(k_{H}\right)$ of the investigated system is given by:

$k_{H}=\frac{\Delta T}{T_{m}-T_{c}}$

The $k_{H}$ a parameter used to measure the glass-forming tendency, for an instant, the higher values of criterion parameters reveal an enhancement in the thermal stability of the formed glass. The values of all these parameters are estimated for the $\mathrm{As}_{30} \mathrm{Te}_{64} \mathrm{Ga}_{6}$ and summarized in Table 2. Both of these parameters $\left(H_{r}\right.$ and $\left.k_{H}\right)$ are enhanced by increasing the value of $\beta$.

\subsubsection{The exothermic heat flow analysis}

Fig. 4 plot shows the exothermic heat flow $\left(\Delta Q_{\text {exo }}\right)$ against temperature $(\mathrm{T})$ at $\beta=5 \mathrm{~K}$ $\min ^{-1}$ in the first crystallization region, as an example. In Fig. 4, $\chi_{T}$ is the crystallized fraction at a given $\mathrm{T}$ expressed by the relation $\chi_{T}=A_{T} / A$, where $A$ is the total area of the peak and $A_{T}$ is the area of the crystallized part (the area between $T_{i}$ and a given temperature $T$ ). Both $T_{i}$ and $T_{f}$ are the initial and final crystallization temperature, respectively.

The same way, the area under the crystallization peak is directly proportional to the total amount of the alloy being crystallized. The ratio between the selected coordinates and the total area of the exothermic peak shows the corresponding crystallization rates, making it possible to plot the curves between the volume crystallization fraction and the temperature.

The experimental graph of the crystalline volume fraction $(\chi)$ shows the typical sigmoid curve as a function of $\mathrm{T}$ at different $\beta$ for the studied system as shown in Fig. 5 (a \& b) (for the two exothermic peaks in the DSC curves) and expressed as follows:

$\chi=\sum_{i=0}^{S} \Delta Q_{\text {exo }} / \sum_{i=0}^{99} \Delta Q_{\text {exo }}$

where $s$ is several points of $\Delta Q_{\text {exo }}$, (namely, $s=0$ to 99).

Now, the relationship between crystallization rate $\left(\frac{d \chi}{d t}\right)$ and the temperature produced by differentiating of the volume crystallized fraction as a function of time $(t)$, which given by the following equation for the maximum crystallization rate:

$\left(\frac{d \chi}{d t}\right)_{p}=\frac{d T}{d t} \times\left(\frac{d \chi}{d T}\right)_{p}=\beta \times\left(\frac{d \chi}{d T}\right)_{p}=\beta \times T_{p}$ 
Figs. 6a and $\mathbf{6 b}$ present the crystallization rate $\left(\frac{d \chi}{d t}\right)$ as a function of temperature for the first and second crystallization peaks, respectively. The values of the maximum crystallization rate evaluated using Eq. (17) and listed in Table 3. From Fig. 5 (a \& b) and Fig. 6 (a \& b), one can conclude that the saturation of crystallization shifts towards the higher temperature as the $\beta$ for the As30Te64Ga6 glassy alloy increases.

\subsection{The glass transition}

The dependence of $T_{g}$ on $\beta$ in the glass transition region could be estimated via two basic formulas; the first equation is the empirical equation originally proposed by Lasocka [45] as follows:

$T_{g}=A_{g}+B_{g} \ln (\beta)$

Where, $A_{g}$ and $B_{g}$ are constants depending on the studied glass alloy. The noticed value of $A_{g}$ articulates or indicates the $T_{g}$ at $\beta=1 \mathrm{~K} \mathrm{~min}^{-1}$, while the observed value of $B_{g}$ indicates the temporal response to the configurational changes within the glass transition region. The validity of this relation to the studied system is shown in Fig. 7. The values of $A_{g}$ and $B_{g}$ constants are computed from the intercept and slope of the fitted line and equal to $5.95 \pm 0.08 \mathrm{~K}$, and $383.10 \pm 0.21 \mathrm{~min}$, respectively.

Continuously, the apparent activation energy of the glass transition $\left(E_{t}\right)$ of the investigated glassy alloy has been estimated using Kissinger's formula [46] and the approximation of Moynihan et al. [47]:

$\ln \left(\beta / T_{g}{ }^{2}\right)=-E_{t} / R T_{g}+$ const.

$\ln (\beta)=-\frac{E_{t}}{R T_{g}}+$ const.

Fig. 8 plots the relationship between $\ln \left(\frac{\beta}{T_{g}{ }^{2}}\right)$ against $1000 / T_{g}$ and also the plot of $\ln (\beta)$ verses 1000/ $T_{g}$ for $\mathrm{As}_{30} \mathrm{Te}_{64} \mathrm{Ga} 6$ chalcogenide glassy. From the slopes of these fitted lines, the activation energy for the glass transition $E_{t}$ was computed and equal to $213.93 \mathrm{~kJ} \mathrm{~mol}^{-1}(51.18$

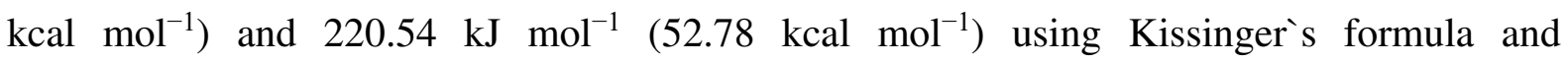
approximation of Moynihan et al., respectively. The observed values of $E_{t}$ lie in the range generally observed for other chalcogenide glasses [42, 48, 49]. The slight difference between the value of $E_{t}$ estimated from the two methods could be related to the individual and proposed approximations. 


\subsection{Fragility index}

The liquid fragility is an important parameter that has beneficial as a basis for organizing data on glass-forming liquids and then facilitating the investigation of relaxation processes and glass transition in the super-cooled liquid state. The fragility index $(F)$ can be computed via the subsequent relation $[50,51]$ :

$F=\frac{E_{t}}{R T_{g} \ln (10)}=\frac{E_{t}}{2.303 R T_{g}}$

Where $E_{t}$ is the activation energy for the glass transition is estimated based on Kissinger's equation. Fig. 9a shows the plot of the liquid fragility as a function of $\left(1000 / T_{g}\right)$ according to Eq. (21). From this figure, we note that the value of $F$ increases with the decrease of $T_{g}$.

\subsection{The cooling rate}

The dependence of the cooling rate $\left(Q_{c}\right)$ on the $T_{g}$ measured during cooling obeys the following equation [52-54]:

$Q_{c}=\frac{R T_{g}^{2}}{E_{t}}=\frac{T_{g}}{2.303 F}$

The plot of the cooling rate as a function of the $T_{g}$ is shown in Fig. $9 \mathbf{b}$. We note from this figure that the cooling rate increases with increasing the $T_{g}$.

\subsection{Activation energy Assessment by the JMA model}

The DSC thermograms have been analyzed by several methods to determine the activation energy of amorphous-crystalline transformation $\left(E_{c}\right)$, the Avrami exponent $(n)$, the frequency factor $\left(K_{0}\right)$, and constants for the investigated glassy alloy.

\subsubsection{Kissinger and Mahadevan Methods}

The activation energy of the amorphous-crystalline transition is originally computed utilizing Kissinger's formula [46] as follows:

$\ln \left(\frac{\beta}{T_{p}^{2}}\right)=-\frac{E_{C}}{R T_{p}}+\ln \left(\frac{E_{C}}{R K_{0}}\right)$

Fig. 10 (a \& b) shows the plots of $\ln \left(\frac{\beta}{T_{p}^{2}}\right)$ against $\left(\frac{1000}{T_{p}}\right)$ for the $\mathrm{As}_{30} \mathrm{Te}_{64} \mathrm{Ga}_{6}$ system. The plots were found to be straight lines. The values for $E_{c}$ equal to 48.37 , and $83.59 \mathrm{kcal} \mathrm{mol}^{-1}$, whereas the values of $K_{0}$ equal to $3.85 \times 10^{19}$, and $15.90 \times 10^{30}$ for both exothermic peaks (peak 1 and peak 2), respectively.

For more confirmation, the activation energy has been computed using the Mahadevan et al. approximation as follows [42]: 
$\ln (\beta)=-\frac{E_{c}}{R T_{p}}+$ const

Fig. 11 (a \& b) show the relationship between $\ln (\beta)$ against $\left(\frac{1000}{T_{p}}\right)$ for the studied glassy alloy. The computed values of, $E_{c}$, which are computed from the slope of a straight line, equals 50.24 and $85.87 \mathrm{kcal} \mathrm{mol}^{-1}$ for the two exothermic peaks (peak1 and peak 2), respectively.

\subsubsection{Augis and Bennett method}

The activation energy was estimated using the method intended by Augis et al. [55] according to the following equation:

$\ln \left(\frac{\beta}{T_{p}}\right)=-\frac{E_{C}}{R T_{p}}+$ const.

Fig. 12 shows the relation between $\ln \left(\frac{\beta}{T_{p}}\right)$ versus $\left(\frac{1000}{T_{p}}\right)$ for the $\mathrm{As}_{30} \mathrm{Te}_{64} \mathrm{Ga}_{6}$ glass. From the slope of this function fitted to the data, the values of $E_{c}$ for the two exothermic peaks (peak1 and peak 2), are estimated which equal to 49.31 and $84.73 \mathrm{kcal} \mathrm{mol}^{-1}$, respectively.

\subsubsection{Gao and Wang method}

The activation energy of the As30Te64 Ga6 alloy has also been evaluated through the method used by Gao et al. [56]. In this method, the maxima of the DSC curves are used and the relationships deduced from the following equations [56]:

$$
\frac{d\left[\ln \left(\frac{d \chi}{d t}\right)_{p}\right]}{d\left[1 / T_{P}\right]}=-\frac{E_{c}}{R}, \frac{\beta E_{c}}{R T_{P} K_{p}}=1
$$

Here $\chi$ is the volume fraction of crystallization, and $\left(\frac{d \chi}{d t}\right)_{p}$ is the maximum crystallization rate which is proportional to the peak height. Fig. 13 shows the plot of $\left(\frac{d \chi}{d t}\right)_{p}$ versus $\left(\frac{1000}{T_{P}}\right)$. According to this method, the value of $E_{c}$ for the studied glassy is computed and it equals 51.17 and $86.99 \mathrm{kcal} \mathrm{mol}^{-1}$ for the two exothermic peaks (peak1 and peak 2), respectively. The crystallization reaction rate constant, $K_{p}$ corresponding to $T_{P}$ was computed from the thermograms by Eq. (26). The values of $K_{p 1},<K_{p 1}>$ for the first exothermic peak and $K_{p 2},<K_{p 2}>$ for the second exothermic peak are computed and listed in Table 3. Here, $\left\langle K_{p 1}\right\rangle$ and $<$ $K_{p 2}>$ represent the average of crystallization reaction rate constants for the exothermic peaks at different $\beta$.

On the other hand, one can compute the kinetic exponent from the experimental values of the $\left(\frac{d \chi}{d t}\right)_{p}$ by the subsequence equation: 
$n_{1,2}=\frac{R T_{P 1,2}^{2}(d \chi / d t)_{p 1,2}}{0.37 \beta E_{c 1,2}}$

Here 1 and 2 refer to the first and second crystallization peaks, respectively. The values of $n_{1}$ and $n_{2}$ for studied glassy alloy are computed and listed in Table 3.

The numerical values of the experimental data, $T_{p}$, and $\left(\frac{d \chi}{d t}\right)_{p}$, are shown in Table 1 and Table 3, respectively. The activation energy value of the crystallization process for the crystallization peaks obtained from Gao and the Wang method (51.17 and $\left.86.99 \mathrm{kcal} \mathrm{mol}^{-1}\right)$, makes it possible to infer through the Eq. (27), the kinematic exponent, n, for each of the experimental $\beta$ for the peaks for the $\mathrm{As}_{30} \mathrm{Te}_{64} \mathrm{Ga}_{6}$, whose values are also presented in Table 3 . The kinetic exponent $n$ was calculated based on the crystallization mechanism of Mahadevan et al. [42] where it was shown that $n$ may be $4,3,2$, or which correlated to different glasscrystal transformation mechanisms: $n=4$, volume nucleation, three-dimensional (3D) growth; $n=3$, volume nucleation, two-dimensional (2D) growth, $n=2$, volume nucleation, onedimensional (1D) growth; $n=1$, surface nucleation, 1D growth from the surface inward. Therefore, taking into account the average values obtained above, $\left\langle n_{1}\right\rangle=4.58$ and $\left\langle n_{2}\right\rangle=$ 4.81 (as shown in Table 3) for the two crystallization peaks, mean size nucleation, 3D growth. The computed $n$ values are not integers. This means that the crystallization occurs through more than one mechanism together $[57,58]$.

\subsubsection{Matusita Method}

Furthermore, the activation energy of the investigated glassy was computed via the Matusita relationship [59]:

$\ln [-\ln (1-\chi)]=-n \ln \beta-1.052 \frac{m E_{c}}{R T}+$ const.

where $(m=n-1)$ is the dimension order parameter and $(n)$ is constant related to the crystallization mechanism. Fig. 14 (a \& b) plots $\ln [-\ln (1-\chi)]$ versus $\left(\frac{1000}{T}\right)$ at different $\beta$ for the studied composition. For the computation of $E_{c}$ we take into consideration the linear region of this plot. From the average $n$ values and $m E_{c}(n=m+1)$, the effective activation energies $E_{c}$ for the studied system is computed and it equals $71.72 \mathrm{kcal} \mathrm{mol}^{-1}$, where $(m=3.58)$ for the first peak but it equals $340.87 \mathrm{kcal} \mathrm{mol}^{-1}$, where $(m=3.81)$ for the second peak.

\subsection{Kinetics parameters of the crystallization}

The reaction rate constant or the kinetic parameter has a temperature dependency based on the Arrhenius equation: 


$$
K(T)=K_{0} \exp \left[-\frac{E_{c}}{R T}\right]
$$

where $E_{c}$ is the crystal growth effective activation energy, $K_{0}$ is the pre-exponential factor or so-called the frequency factor, and $R$ is the universal gas constant $\left(8.314 \mathrm{~J} \mathrm{~K}^{-1} \mathrm{~mol}^{-1}\right)$. Besides, a kinetic parameter, $K(T)$, with an Arrhenian temperature dependence, describes the stability parameters. According to Surinach et al. [60] and Hu and Jiang [61] the thermal stability of glassy materials estimates via two criteria as follows:

$K\left(T_{g}\right)=K_{0} \exp \left[-\frac{E_{c}}{R T_{g}}\right], \quad K\left(T_{p}\right)=K_{0} \exp \left[-\frac{E_{c}}{R T_{p}}\right]$

The values of these two parameters indicate the tendency of the glass to dissolve upon heating, whereas the glass formation is a kinetic process. The higher their values, the greater the tendency to depreciate.

According to the obtained values of $E_{c}$ and $K_{0}$, that resulted from the Kissinger method, the kinetic parameters $K(T)$ of the studied alloy were computed by Eq. (30). These calculations were made to compare the stability sequence of the studied substance from the parameters quoted with the corresponding sequence computed from the stability parameters based on the characteristic temperatures. The $K\left(T_{g}\right)$ and $K\left(T_{p}\right)$ as a function of $T_{g}$ and $T_{p}$ for the studied sample are shown in Fig. 15 (a \& b). According to the previous work [62, 63], the smaller the values of $K\left(T_{g}\right)$ and $K\left(T_{p}\right)$ parameters, the better the ability of the material to form glass. So the data for both $K\left(T_{g}\right)$ and $K\left(T_{p}\right)$ indicate that the thermal stability decrease with increasing $\beta$.

The parameter $H_{r}$ is a stability factor depends on characteristic temperatures. Here, a stability criterion is defined as follows [64]:

$K_{r}(T)=K_{0} \exp \left[-\frac{H_{r} E_{c}}{R T}\right]$

where $T$ is an arbitrary temperature between $T_{g}$ and $T_{p}$. The theoretical definition of the parameter $K_{r}(T)$ has relied on the analysis of the relation between the parameters $K(T)$ and $K_{r}(T)$. By differentiating Eq. (29) and Eq. (31) concerning temperature and rewriting each parameter results, one can get the following relations:

$\frac{\Delta K_{r}}{K_{r} \Delta T}=\frac{H_{r} E_{c}}{R T^{2}}, \quad \frac{\Delta K}{K \Delta T}=\frac{E_{c}}{R T}$

. Then, using Eq. (31), the data for $K \_r\left(T \_g\right)$ and $K \_r\left(T \_p\right)$ were also calculated as a function of as shown in Fig.16 confirming that the stability orders increased with increasing $\beta$.

It can be concluded that the change in the parameter $K_{r}(T)$ is equal to $H_{r}$ times the parameter $K(T)$. Therefore, similar to $K(T)$ criteria, the smaller the $K_{r}(T)$ values, the greater the thermal stability of the glass. The obvious advantage of this method is that, it can evaluate 
the stability of the glass over a wide range of temperatures other than only one temperature, such as $T_{g}$ or $T_{p}$. Then, using Eq. (31), the data of $K_{r}\left(T_{g}\right)$ and $K_{r}\left(T_{p}\right)$ were also computed as a function of $\beta$ as shown in Fig. 16 confirming that that the stability orders increased with increasing $\beta$.

\section{Conclusions}

In summary, the chalcogenide of the $\mathrm{As}_{30} \mathrm{Te}_{64} \mathrm{Ga}_{6}$ bulk alloy is prepared using the meltquenching technique. Fitting of the kinetic model to isothermal transformation-rate data, as exhibited by DSC scans. The characteristic temperatures $\left(T_{\mathrm{g}}, T_{\mathrm{c}}, T_{\mathrm{p}}\right.$, and $\left.T_{\mathrm{m}}\right)$ were determined, and hence the glass transition activation energy, amorphous crystallization, and crystallization transformations. The kinetics of the crystallization was studied by non-isothermal DSC, XRD, and the values of the activation energy and Avrami index values were calculated by the Matausita method also the activation energy was deduced by other methods. The results appear strong dependence on the heating rate of the activation energy for the crystalline peaks. Avrami exponent is close to 4.58 and 4.81 thus corresponding to complex processes that include different mechanisms. On the other hand, the thermal stability for As $30 \mathrm{Te}_{64} \mathrm{Ga}$ g glassy alloy at different heating rate has been computed via various criteria. The $K_{\mathrm{r}}(T)$ criterion has been considered in the present framework for the determination of glass stability based on DSC data. The obtained results of the $K\left(T_{\mathrm{g}}\right), K\left(T_{\mathrm{p}}\right), K_{\mathrm{r}}\left(T_{\mathrm{g}}\right)$, and $K_{\mathrm{r}}\left(T_{\mathrm{p}}\right)$ agree satisfactorily with the $\Delta T$, $H_{\mathrm{r}}, H^{\prime}$ and $S$ criteria for the studied glassy alloy. The observed data of the thermal stability criteria indicate that the studied glass is the most stable, and the stability orders at various heating rate increases as the criterion parameters have high values.

\section{Acknowledgment:}

The research group extend their appreciation to the Deputyship for Research \& Innovation (DRI), Ministry of Education in Saudi Arabia for funding this work through the grant number "375213500". Also, the authors would like to extend their sincere appreciation to the central laboratory at Jouf University for support this study.

\section{References}

1. K. Tanabe, A.F. i Morral, H.A. Atwater, D.J. Aiken, M.W. Wanlass, Appl. Phys. Lett. 89, 102106 (2006) 
2. J.F. Geisz, D.J. Friedman, J.S. Ward, A. Duda, W.J. Olavarria, T.E. Moriarty, J.T. Kiehl, M.J. Romero, A.G. Norman, K.M. Jones, Appl. Phys. Lett. 93, 123505 (2008)

3. K. Volz, D. Lackner, I. Nemeth, B. Kunert, W. Stolz, C. Baur, F. Dimroth, A.W. Bett, J. Cryst. Growth 310, 2222 (2008)

4. B.J. Fernandes, K. Ramesh, N.K. Udayashankar, Mater. Sci. Eng. B 246, 34 (2019)

5. R. Zallen, C.M. Penchina, Am. J. Phys. 54, 862 (1986)

6. A. Burian, P. Lecante, A. Mosset, J. Galy, J. M. Tonnerre, D. Raoux, J. Non-Cryst. Solids 212, 23 (1997)

7. H. Endo, H. Hoshino, H. Ikemoto, T. Miyanaga, J. Phys. Condens. Matter 12, 6077 (2000)

8. D.C. Kaseman, I. Hung, K. Lee, K. Kovnir, Z. Gan, B. Aitken, S. Sen, J. Phys. Chem. B 119, $2081(2015)$

9. P. Jóvári, P. Lucas, Z. Yang, B. Bureau, I. Kaban, B. Beuneu, J. Bednarčik, J. Am. Ceram. Soc. 97, 1625 (2014)

10. J.B. Vaney, J. Carreaud, C. Morin, G. Delaizir, A. Piarristeguy, M. Colas, J. Cornette, R. Le Parc, E. Alleno, J. Monnier, M. Ribes, J. Am. Ceram. Soc. 100, 2840 (2017)

11. M. Dongol, M.M. Hafiz, M. Abou-Zied, A.F. Elhady, Appl. Surf. Sci. 185, 1 (2001)

12. P. Jóvári, P. Lucas, Z. Yang, B. Bureau, I. Kaban, B. Beuneu, C. Pantalei, J. Bednarčik, J. Non-Cryst. Solids 433, 1 (2016)

13. S. Murugavel, K.V. Acharya, S. Asokan, J. Non-Cryst. Solids 191, 327 (1995)

14. M. Dongol, Egypt. J. Solids 25, 33 (2002)

15. A.M. Abd-Elnaiem, R.M. Hassan, H.R. Alamri, H.S. Assaedi, J. Mater. Sci.: Mater. 31, $13204(2020)$

16. A.M. Abd-Elnaiem, S. Moustafa, Process. Appl. Ceram. 12, 209 (2018)

17. N. Manikandan, M. Paulraj, S. Asokan, J. Non-Cryst. Solids 355, 58 (2009)

18. R.M. Hassan, A.Z. Mahmoud, M.A. Abdel-Rahim, H.S. Assaedi, S.W. Alraddadi, A.M. Abd-Elnaiem, J. Inorg. Organomet. Polym. Mater. (2021)

19. M. Mohamed, A.M. Abd-Elnaiem, R.M. Hassan, M.A. Abdel-Rahim, M.M. Hafiz, Appl. Phys. A, 123, 511 (2017)

20. N. Rysava, T. Spasov, L. Tichy, J. Therm. Anal. 32, 1015 (1987)

21. A. Giridhar, S. Mahadevan, J. Non-Cryst. Solids 51, 305 (1982)

22. A.M. Abd-Elnaiem, S.I. Hussein, H.S. Assaedi, A.M. Mebed, Polym. Bull. (2020). https://doi.org/10.1007/s00289-020-03301-5

23. W.H. Wei, L. Fang, X. Shen, R.P. Wang, Phys. Status Solidi B 250, 59 (2013)

24. A.M. Mebed, A.M. Abd-Elnaiem, Pro. Nat. Sci.-Mater. 24, 599 (2014)

25. A.M. Abd-Elnaiem, Gh. Abbady, J. Alloys Compd. 818, 152880 (2019) 
26. Gh. Abbady, A.M. Abd-Elnaiem, Phase Transit. 92, 667 (2019)

27. M.A. Dabban, N.M. Abdelazim, A.M. Abd-Elnaiem, S. Mustafa, M.A. Abdel-Rahim, Mater. Res. Innov. 22, 324 (2018)

28. A. Loffe, A. Regel, Progress in Semiconductors 4, 89 (1960)

29. A. Zakery, S. Elliott, J. Non-Cryst. Solids 330, 1 (2003)

30. S. Fayek, A. Maged, M. Balboul, Vacuum 53, 447 (1999)

31. M. Fadel, Vacuum 48, 73 (1997)

32. L. Zhenhua, J. Non-Cryst. Solids 127, 298 (1991)

33. L. Tichý, H. Ticha, J. Non-Cryst. Solids 189, 141 (1995)

34. J.H. Schachtschneider, R.G. Snyder, Spectrochim. Acta 19, 117 (1963)

35. L. Pauling, "The Nature of the chemical bond", Cornell university press Ithaca, NY, 1960.

36. M. Rashad, H.A. Saudi, H.M.H. Zakaly, S.A.M. Issa, A.M. Abd-Elnaiem, Opt. Mater. 112, $110613(2021)$

37. M.F. Thorpe, J. Non-Cryst. Solids 57, 355 (1983)

38. R. Sanderson, "Inorganic Chemistry", (New Delhi: Affiliated East, in, West Press PUT Ltd, 1971.

39. A.M. Abd-Elnaiem, M. Mohamed, R.M. Hassan, A.A. Abu-Sehly, M.A. Abdel-Rahim, M.M. Hafiz, Mater. Science-Poland 35, 335 (2017)

40. M.A. Abdel-Rahim, M.M. Hafiz, A.Y. Abdel-Latief, A.M. Abd-Elnaiem, A. Elwhab B. Alwany, Appl. Phys. A 119, 881 (2015)

41. A.M. Abd-Elnaiem, M. Mohamed, R.M. Hassan, M.A. Abdel-Rahim, A.A. Abu-Sehly, M.M. Hafiz, Mater. Science-Poland 36, 193 (2018)

42. S. Mahadevan, A. Giridhar, A.K. Singh, J. Non-Cryst. Solids 88, 11 (1986)

43. M. Saad, M. Poulin, Mater. Sci. Forum 19, 11 (1987)

44. A. Hrubý, Czechoslov. J. Phys. B 22, 1187 (1972)

45. M. Lasocka, Mater. Sci. Eng. 23, 173 (1976)

46. H.E. Kissinger, Anal. Chem. 29, 1702 (1957)

47. C.T. Moynihan, A.J. Easteal, M.A. De Bolt, J. Tucker, J. Am. Ceram. Soc. 59, 12 (1976)

48. M.A. Abdel-Rahim, A.Y. Abdel-Latif, A. El-Korashy, G.A. Mohamed, J. Mater. Sci. 30, $5737(1995)$

49. J. Vázquez, C. Wagner, P. Villares, R. Jiménez-Garay, Acta Mater. 44, 4807 (1996)

50. K. Chebli, J.M. Saiter, J. Grenet, A. Hamou, G. Saffarini, Physica B 304, 228 (2001)

51. M.M. Wakkad, E.K. Shokr, S.H. Mohamed, J. Non-Cryst. Solids 265, 157 (2000)

52. G.M. Bartenev, In Dokl. Akad. Nauk SSSR. Vol. 76. No. 2. (1951) 
53. I. Gutzow, J. Schmelzer. “The vitreous state”. Berlin: Springer, 1995.

54. P.G. Debenedetti, "Metastable liquids: concepts and principles". Princeton University Press, 1996.

55. J. Augis, J. Bennett, J. Therm. Anal. Calorim. 13, 283 (1978)

56. Y.Q. Gao, W. Wang, J. Non-Cryst. Solids 81, 129 (1986)

57. P. Duhaj, D. Barančok, A. Ondrejka, J. Non-Cryst. Solids 21, 411 (1976)

58. K. Tanaka, Phys. Rev. B 39, 1270 (1989)

59. K. Matusita, T. Komatsu, R. Yokota, J. Mater. Sci. 19, 291 (1984)

60. S. Surinach, M.D. Baro, M.T. Clavaguera-Mora, N. Clavaguera, J. Mater. Sci. 19, 3005 (1984)

61. L. Hu, Z. Jiang, J. Chin. Ceram. Soc. 18, 315 (1990)

62. J. Vazquez, P.L. Lopez-Alemany, P. Villares, R. Jimenez-Garay, J. Alloys Compd. 354, $153(2003)$

63. A. Yadav, M.S. Dahiya, A. Hooda, P. Chand, S. Khasa, Solid State Sci. 70, 54 (2017)

64. B.S. Patial, N. Thakur, S.K. Tripathi, J. Therm. Anal. Calorim. 106, 845 (2011) 
Figures

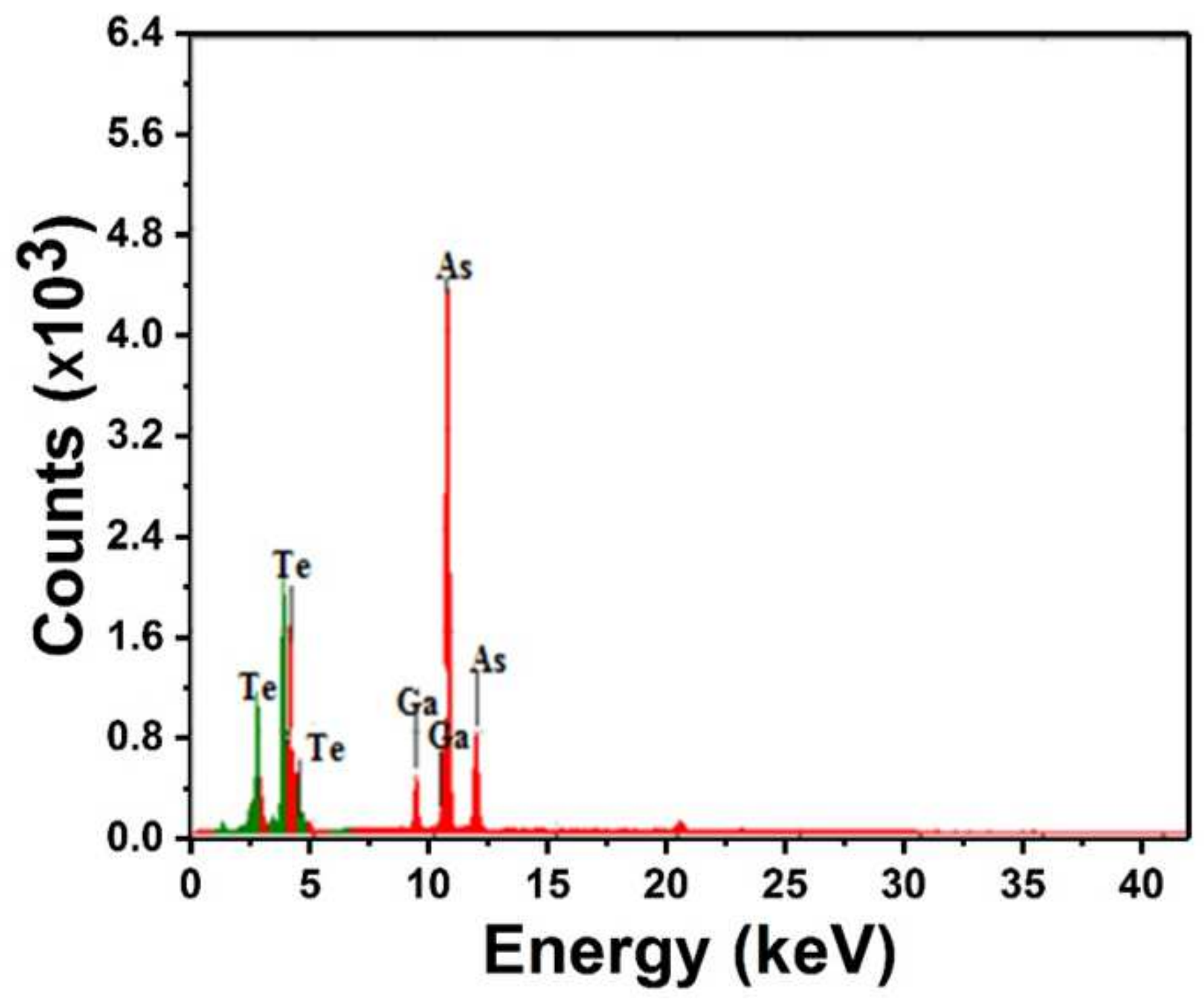

Figure 1

Energy dispersive X-ray (EDX) spectrum of the As30Te64Ga6 bulk alloy. 


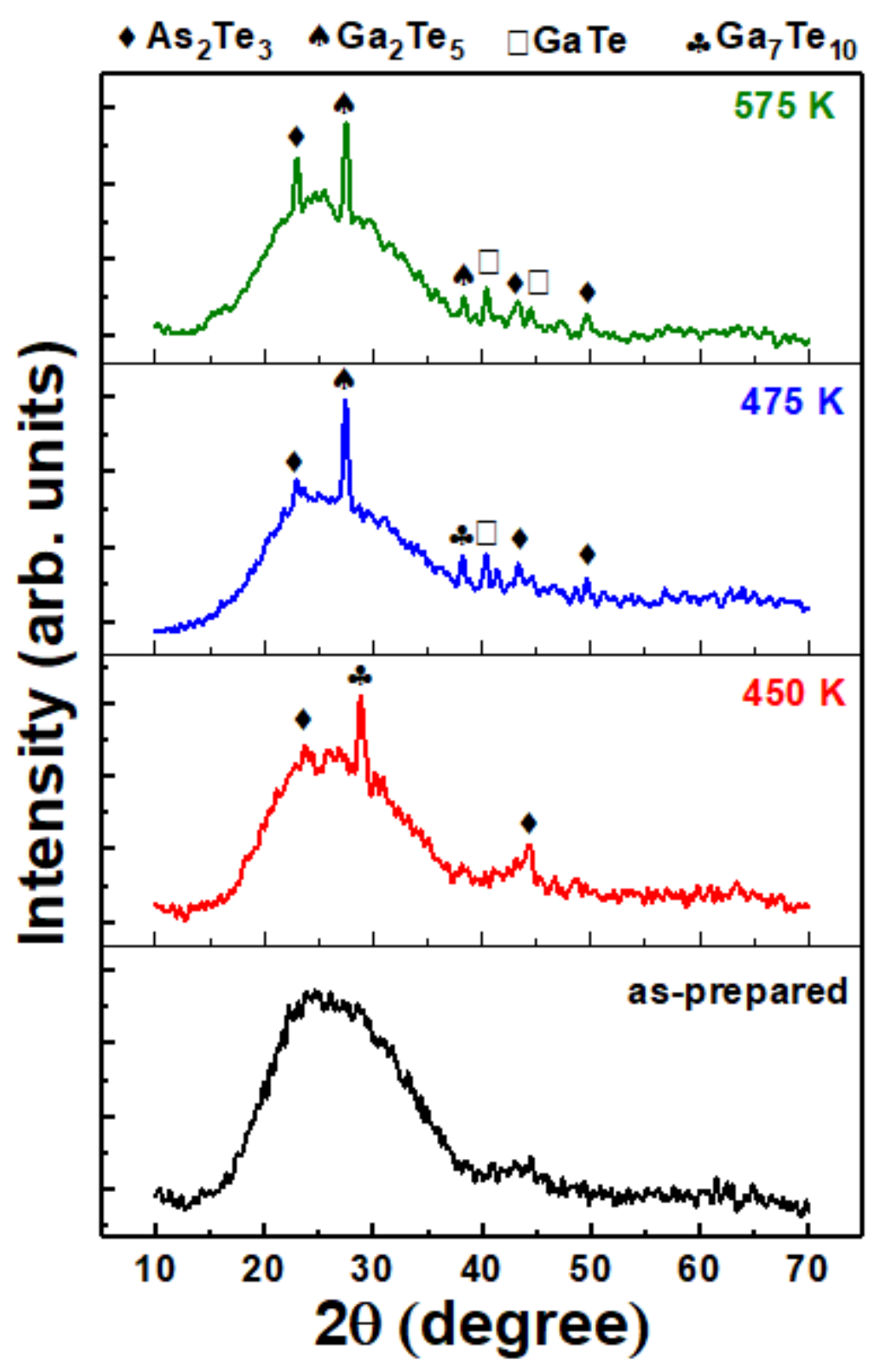

Figure 2

X-ray diffraction patterns of the as-prepared As30Te64Ga6 glassy alloy and annealed samples at 450, 475 , and $575 \mathrm{~K}$ for $1 \mathrm{~h}$ under vacuum. 


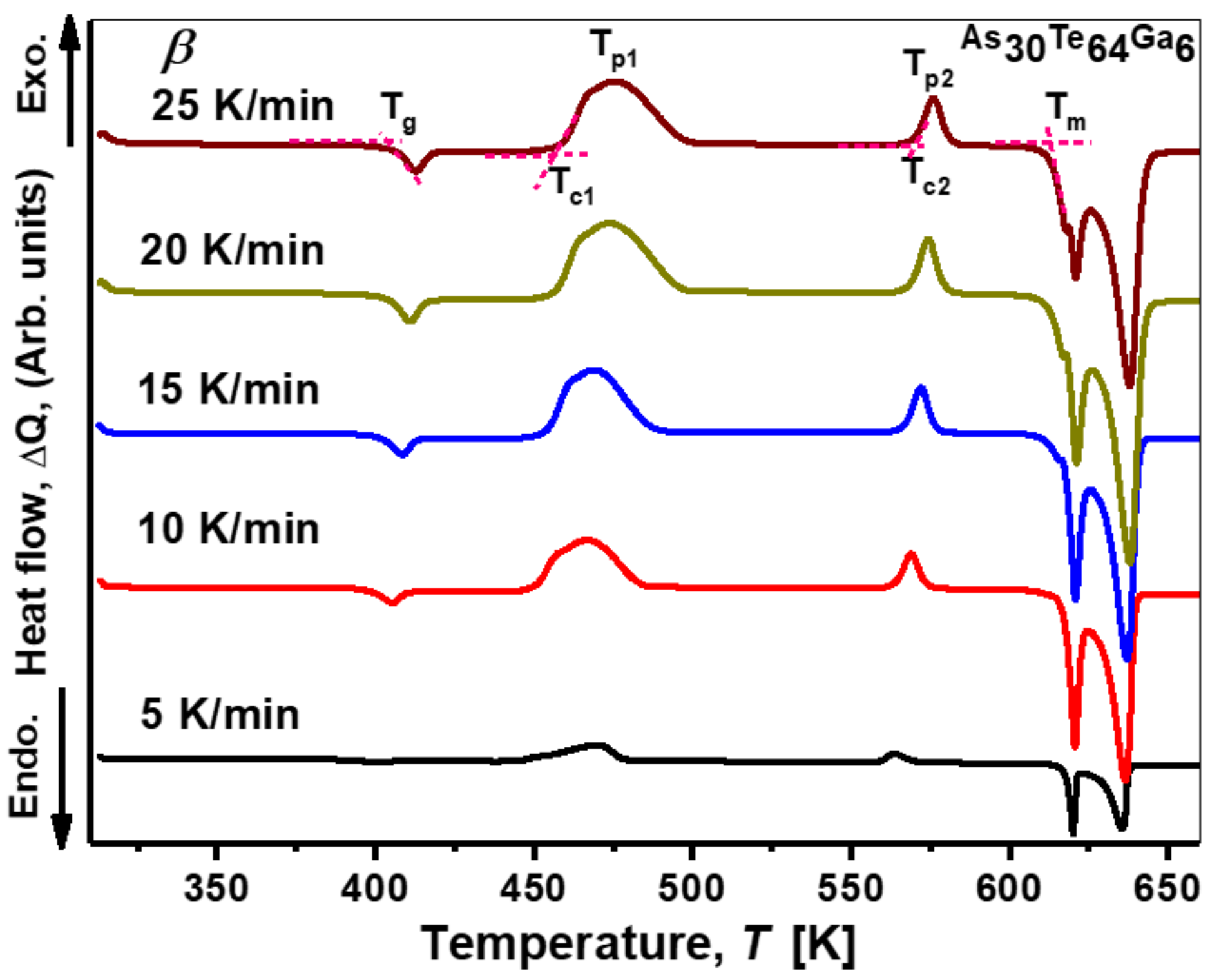

Figure 3

DSC thermo-grams for bulk the As30Te64Ga6 glass at the different heating rates ( $\beta$ ). 


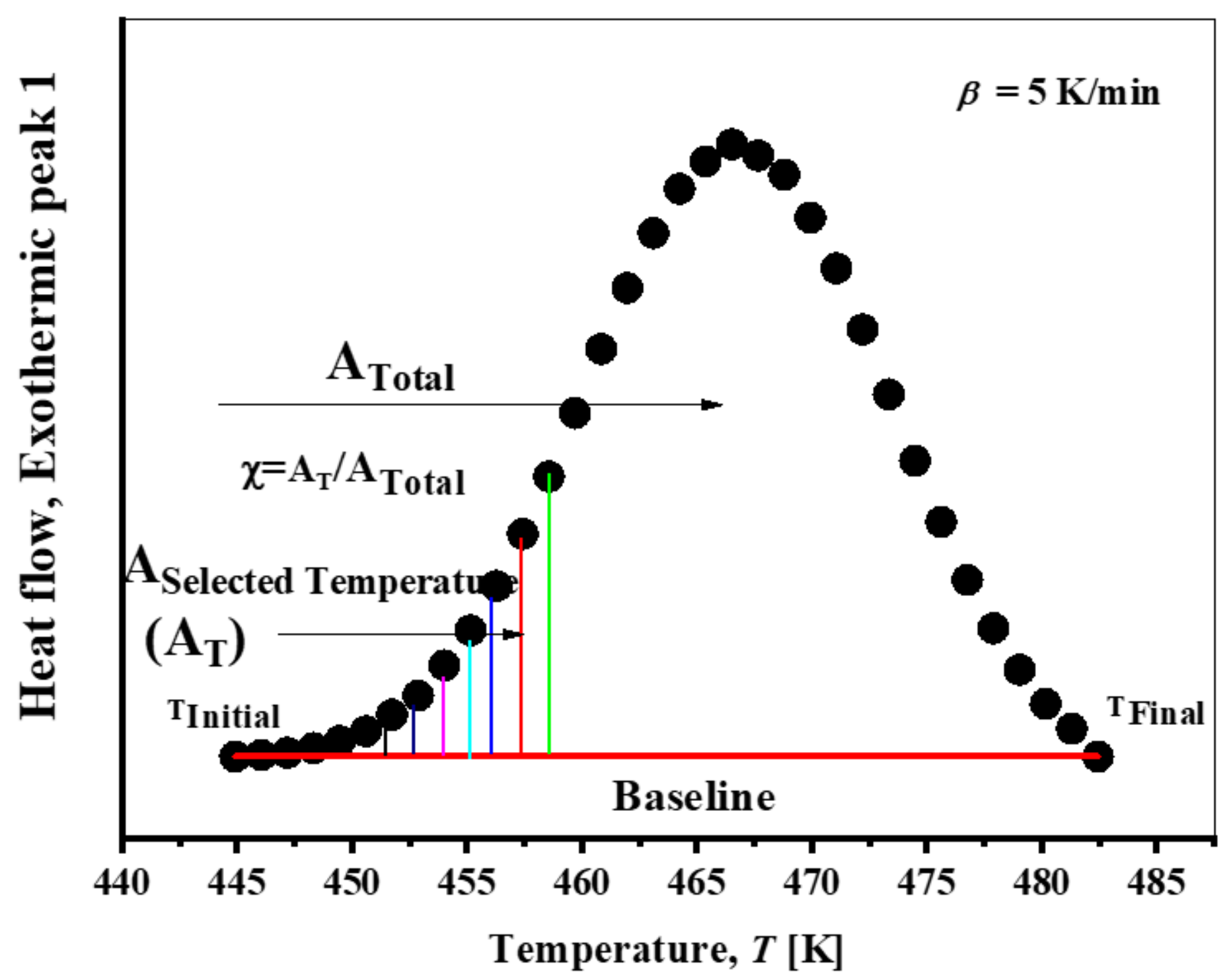

Figure 4

DSC trace for bulk As30Te64Ga6 glass at a heating rate $\beta=5 \mathrm{~K} \mathrm{~min}-1$; (the first exothermic peak), the lined area AT shown between $\mathrm{Ti}$ and $\mathrm{Tf}$ of the peak, $\mathrm{Ti}, \mathrm{Tf}$, and $\mathrm{T}$ are according to the text. 

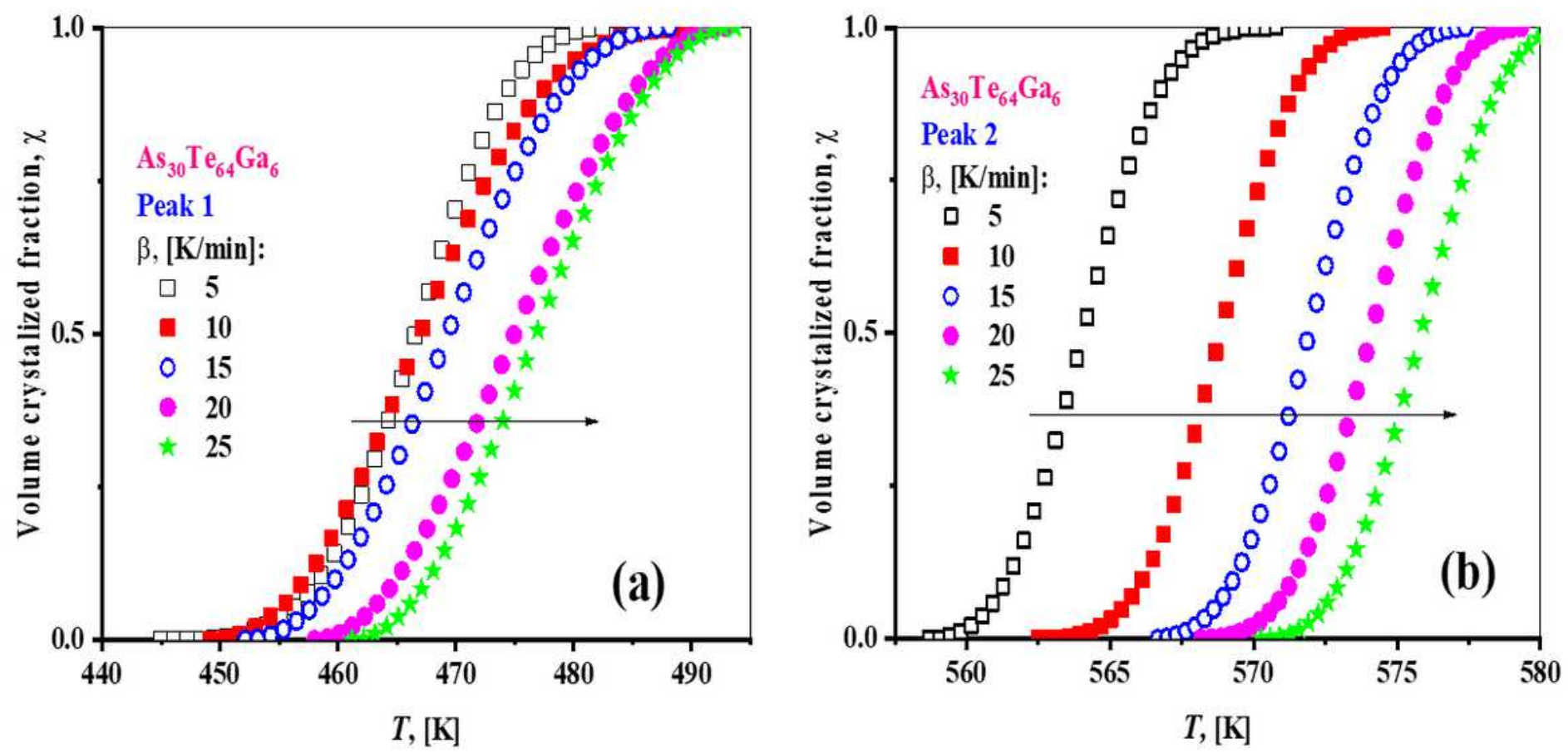

Figure 5

The typical sigmoid curve of the volume fraction crystallized $(X)$ as a function of temperature $(T)$ for bulk As30Te64Ga6 glass alloy at the different heating rates $(\beta)$.
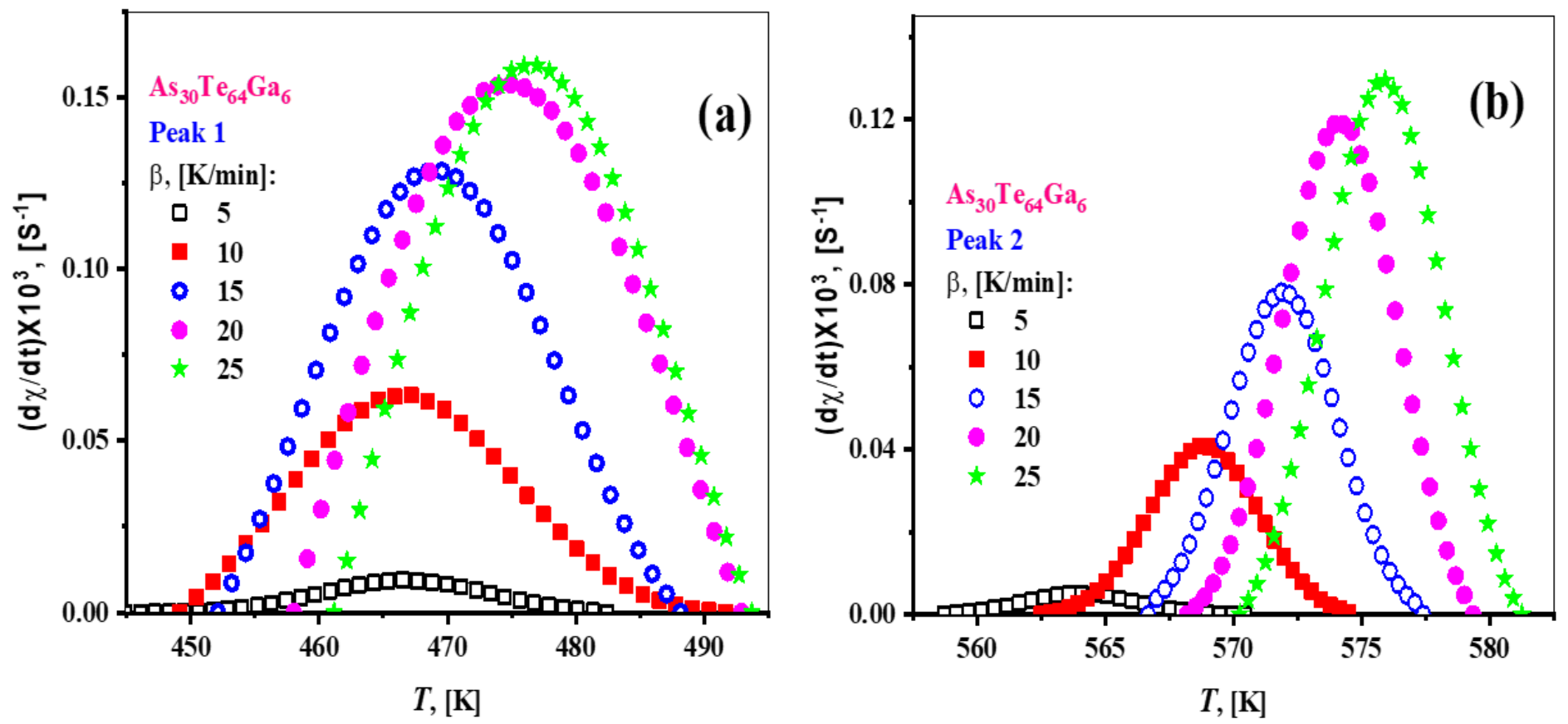

Figure 6

See the Supplemental Files section for the complete figure caption 


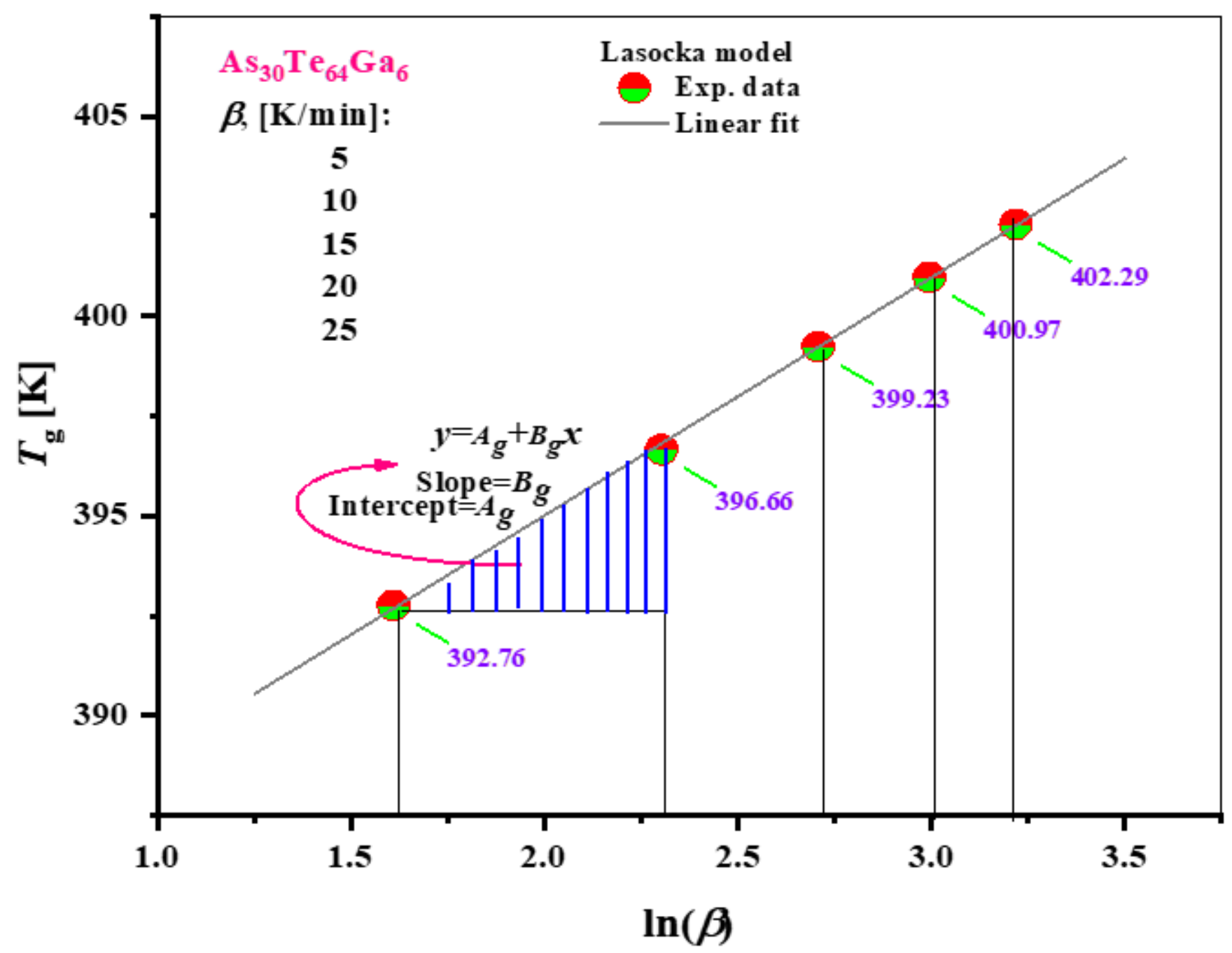

Figure 7

The test of the validity of relation's Lasocka for bulk As30Te64Ga6 glass alloy at different heating rates $(\beta)$. 

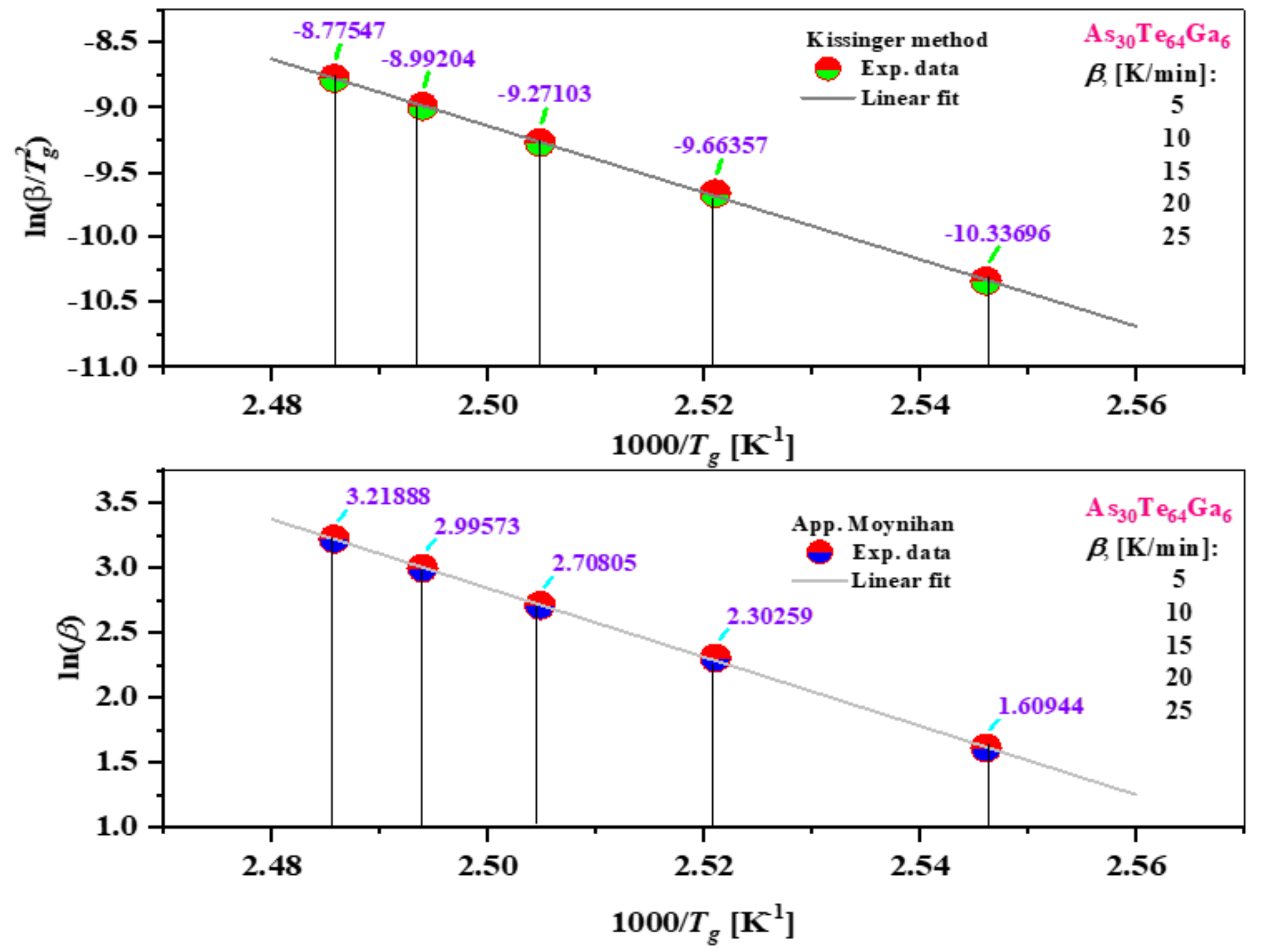

Figure 8

See the Supplemental Files section for the complete figure caption 

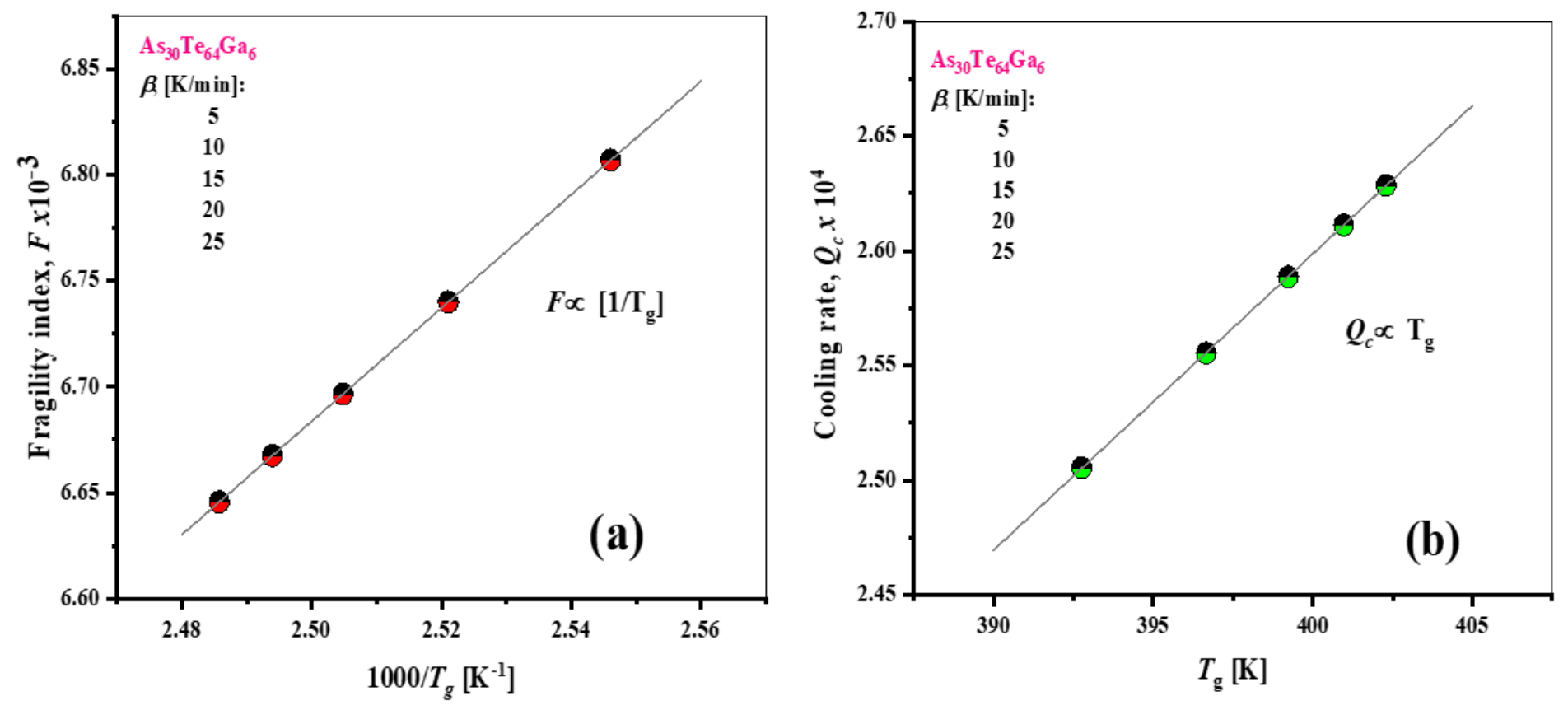

Figure 9

See the Supplemental Files section for the complete figure caption 

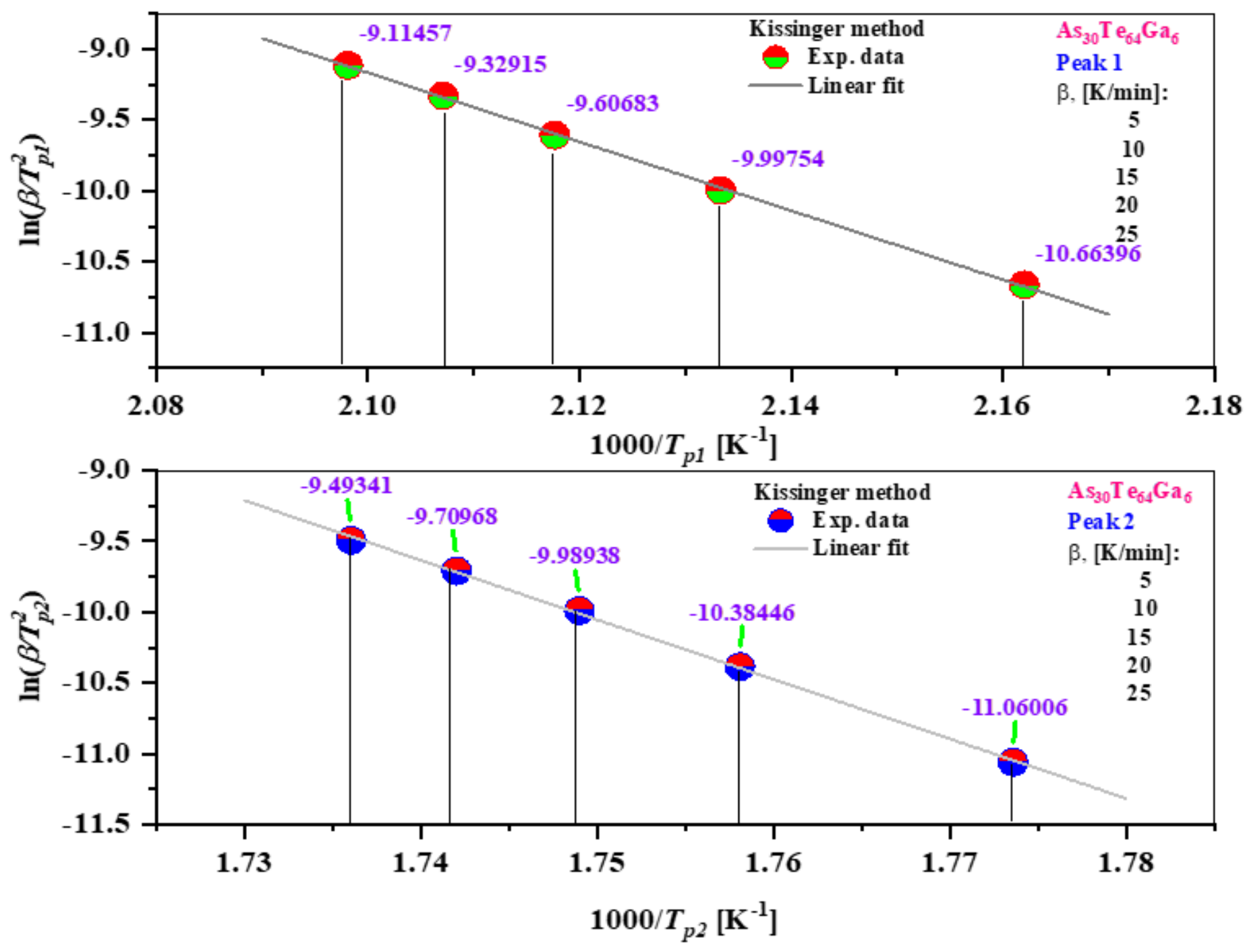

Figure 10

See the Supplemental Files section for the complete figure caption 

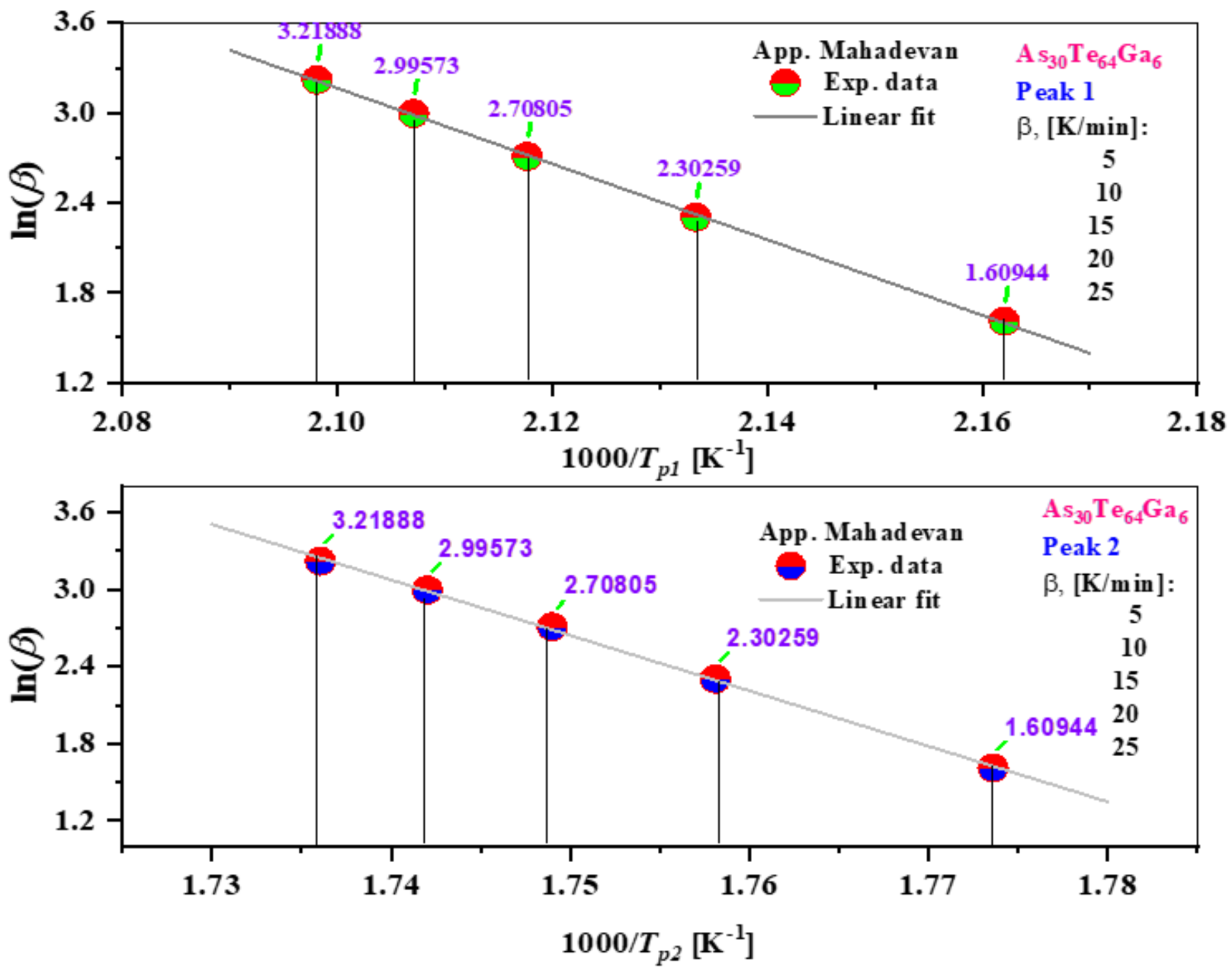

Figure 11

See the Supplemental Files section for the complete figure caption 

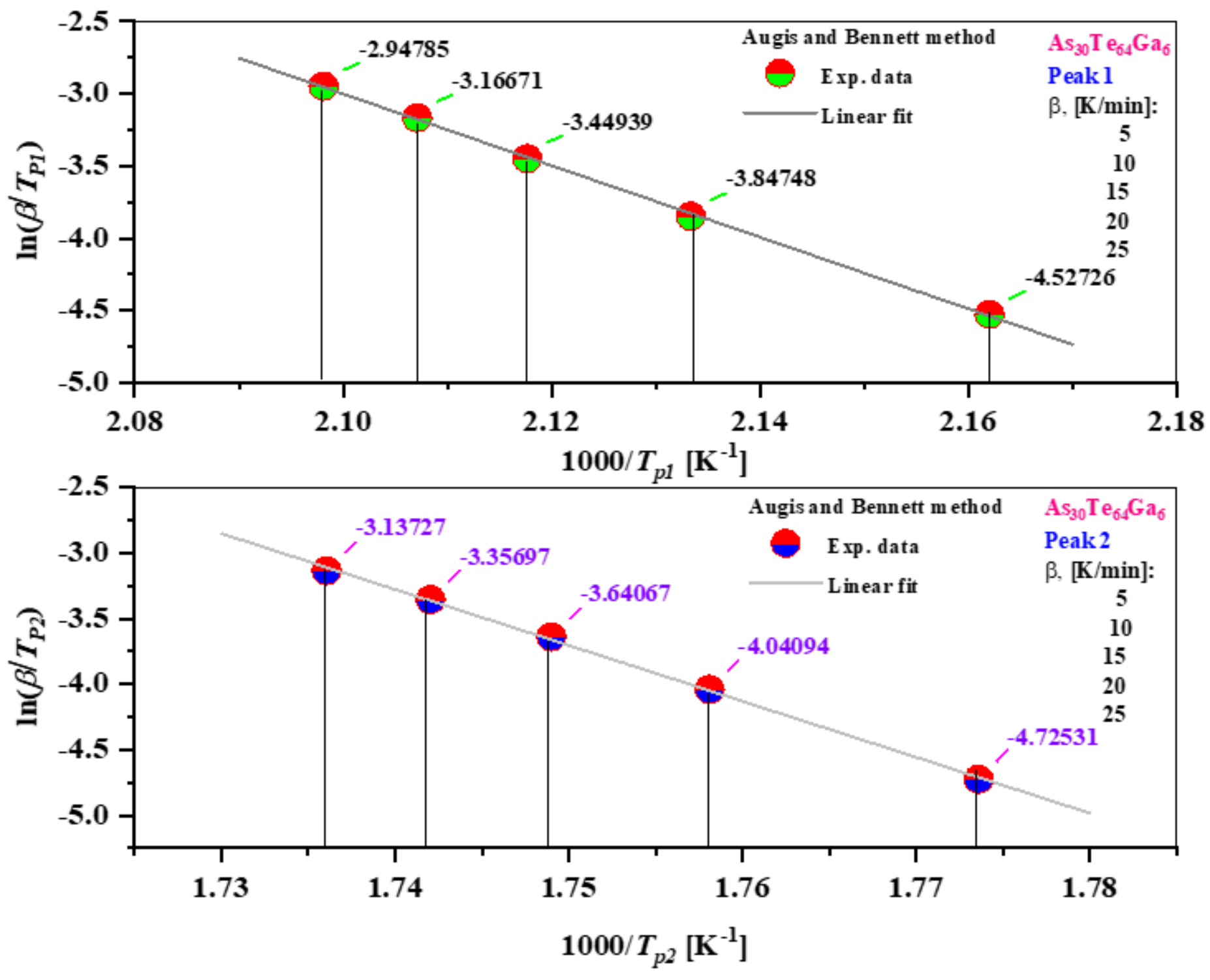

Figure 12

See the Supplemental Files section for the complete figure caption 

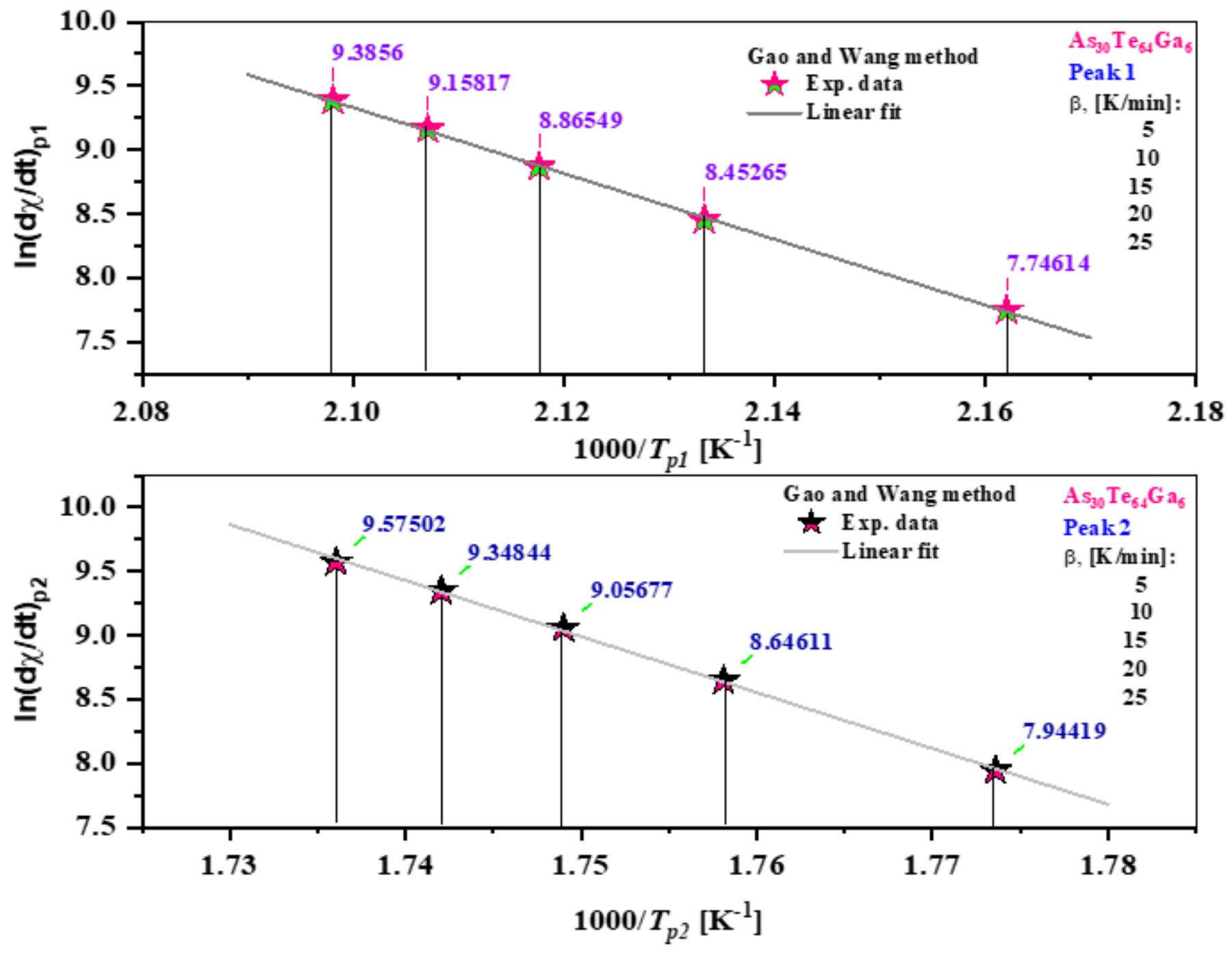

Figure 13

See the Supplemental Files section for the complete figure caption 

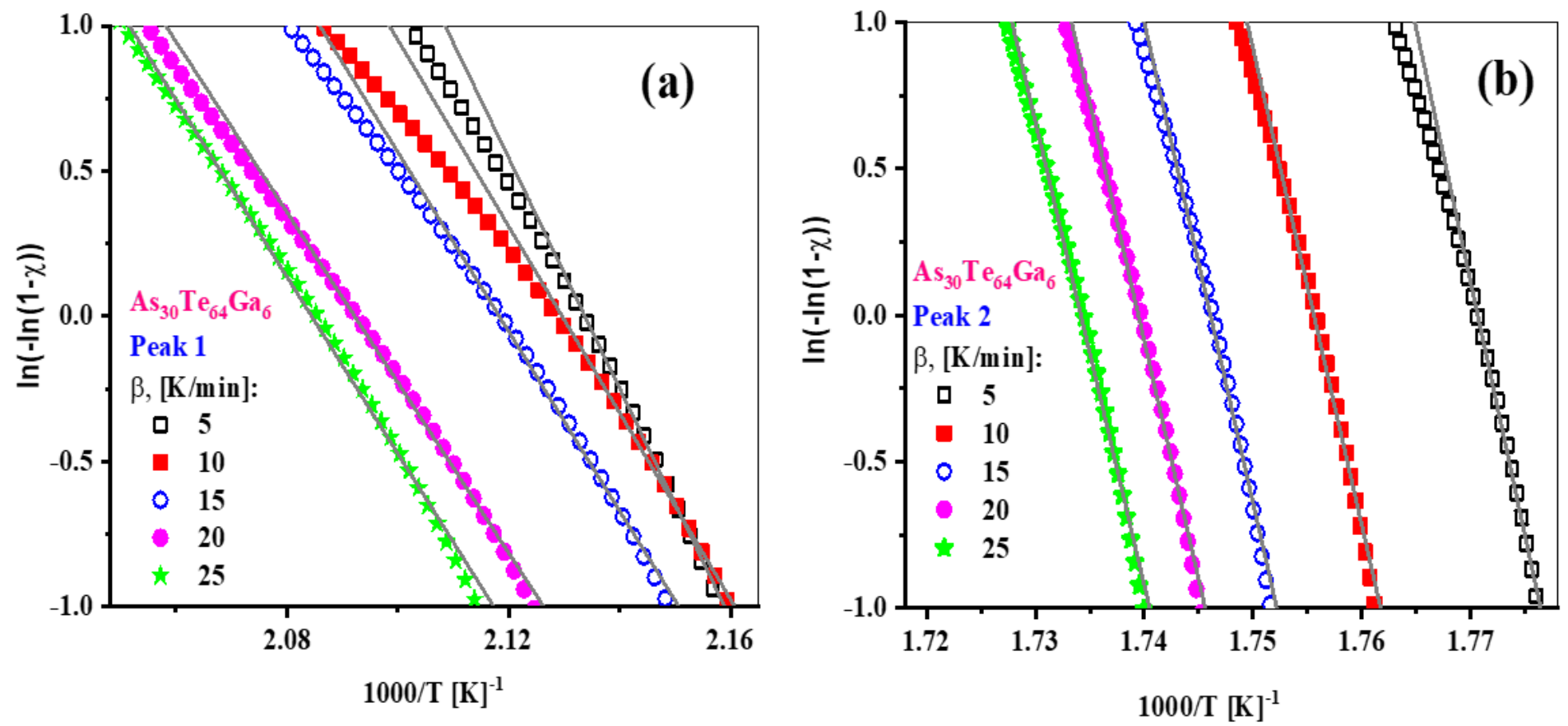

Figure 14

See the Supplemental Files section for the complete figure caption
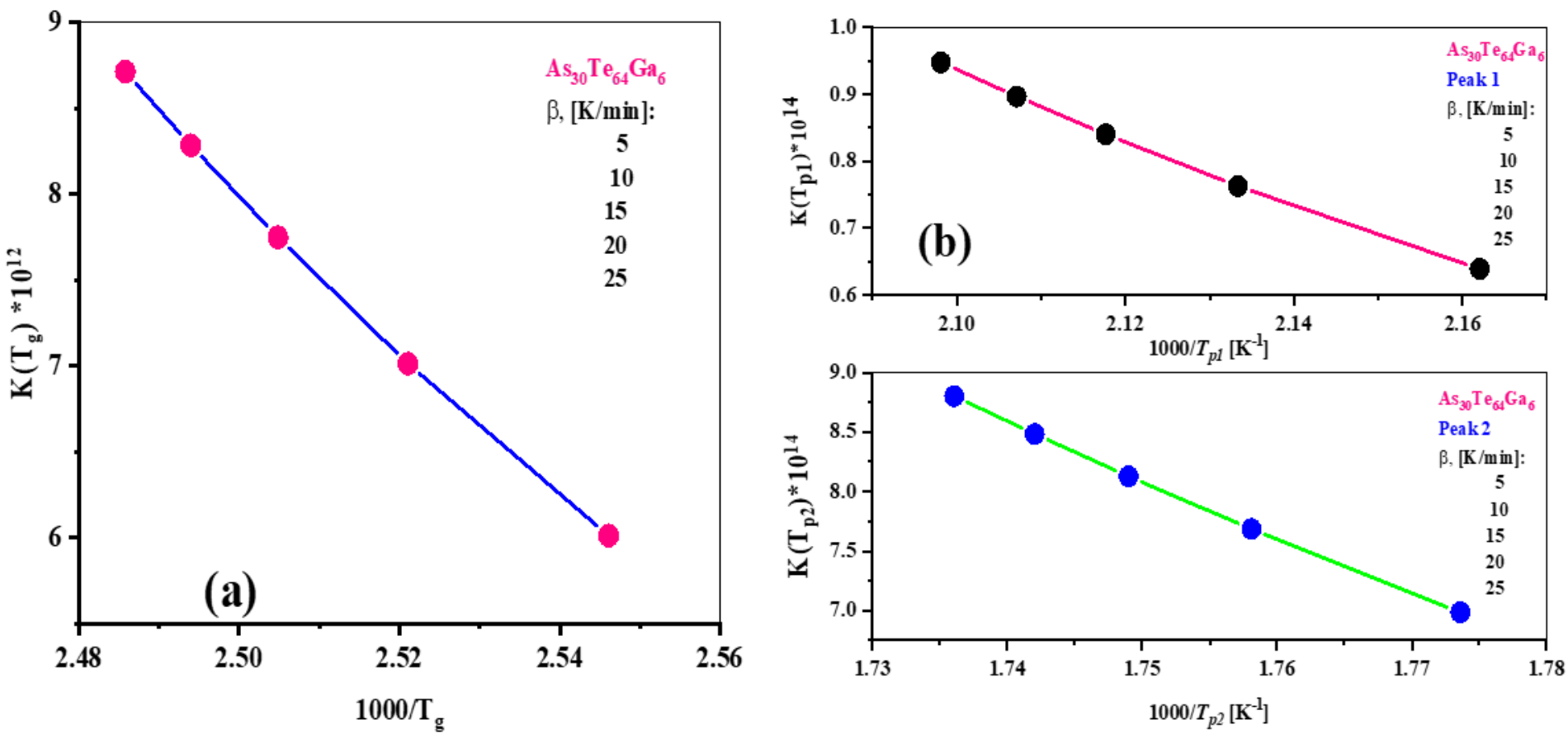

Figure 15

See the Supplemental Files section for the complete figure caption 

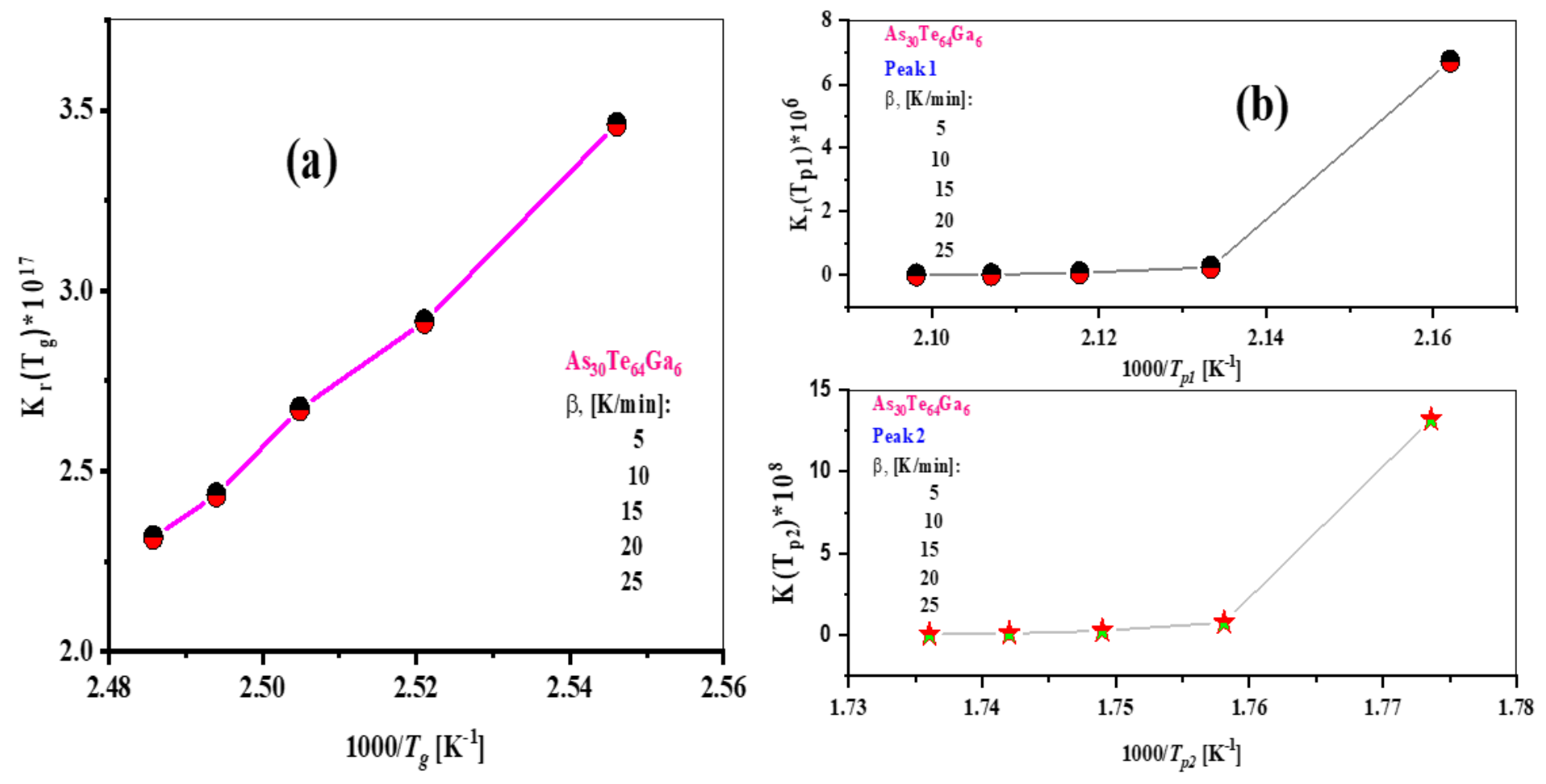

Figure 16

See the Supplemental Files section for the complete figure caption

\section{Supplementary Files}

This is a list of supplementary files associated with this preprint. Click to download.

- ListofFigures.docx

- ListofTables.docx 